\title{
Exploration of Enceladus and Titan: investigating ocean worlds' evolution and habitability in the Saturn system
}

\author{
Giuseppe Mitri ${ }^{1,2}$ D Jason Barnes ${ }^{3}$ - Athena Coustenis ${ }^{4} \cdot$ Enrico Flamini $^{1}$. \\ Alexander Hayes $^{5} \cdot$ Ralph D. Lorenz ${ }^{6}$ - Marco Mastrogiuseppe ${ }^{7}$. \\ Roberto Orosei ${ }^{8} \cdot$ Frank Postberg $^{9} \cdot \operatorname{Kim~Reh}^{10} \cdot$ Jason M. Soderblom $^{11}$. \\ Christophe Sotin $^{10}$. Gabriel Tobie ${ }^{12}$. Paolo Tortora ${ }^{13}$. \\ Veronique Vuitton $^{14} \cdot$ Peter Wurz $^{15}$
}

Received: 2 August 2020 / Accepted: 23 June 2021/ Published online: 22 July 2021

(C) The Author(s) 2021

\begin{abstract}
We present a White Paper with a science theme concept of ocean world evolution and habitability proposed in response to ESA's Voyage 2050 Call with a focus on Titan and Enceladus in the Saturn system. Ocean worlds in the outer Solar System that possess subsurface liquid water oceans are considered to be prime targets for extra-terrestrial life and offer windows into Solar System evolution and habitability. The Cassini-Huygens mission to the Saturn system (2004-2017) revealed Titan with its organic-rich evolving world with terrestrial features and Enceladus with its active aqueous environment to be ideal candidates to investigate ocean world evolution and habitability. Additionally, this White Paper presents a baseline for a multiple flyby mission with a focused payload as an example of how ocean world evolution and habitability in the Saturn system could be investigated building on the heritage of the Cassini-Huygens mission and complementing the recently selected NASA Dragonfly mission.
\end{abstract}

Keywords Enceladus · Titan · Ocean worlds · Voyage 2050

\section{Introduction}

\subsection{Overview}

Recent observations from the ground and in space have shown that Earth is not the only place in the Solar System to possess exposed surface liquid. Observations have

Giuseppe Mitri

giuseppe.mitri@unich.it

Extended author information available on the last page of the article 
provided evidence of subsurface liquid water oceans covered by icy shells on multiple objects in the Solar System, called ocean worlds, including the icy moons of Jupiter (Europa, Ganymede, and Callisto) and of Saturn (Titan and Enceladus) as well as dwarf planets (Ceres and Pluto) (see [83] for a review and De [33]). The NASA/ESA/ASI Cassini-Huygens mission (2004-2017) has done much to advance our understanding of the Saturn system in general and Titan and Enceladus in particular, and has shown these satellites of Saturn to be two favourable locations in the Solar System in our quest for a better understanding of the evolution of the Solar System and its habitable potential. Both Saturnian moons possess energy sources, liquid habitats, nutrients (organic compounds), and transport cycles of liquid moving nutrients and waste, all necessary ingredients for habitability $[46,92]$. Titan is the only active extraterrestrial alkanological system in the Solar System (analogous to the Earth's hydrological system), including an organically rich atmosphere, hydrocarbon lakes and seas on the surface and a liquid water subsurface ocean. Enceladus has active plumes composed of multiple jets containing complex organics and water vapour and likely connected to its liquid water subsurface ocean. Along with their energy sources, these bodies are prime environments in which to investigate the conditions for the emergence of life and habitability conditions of ocean worlds in the outer Solar System, as well as the origin and evolution of gas giant planetary systems, in a single mission.

The Cassini-Huygens mission also introduced new first order scientific questions for geologists, astrobiologists, organic chemists, and planetary scientists, that remain unanswered to date $[30,36,117,151]$. On Titan, its resemblance to primitive Earth and the presence of a rich mixture of organic material in contact with liquid reservoirs, which may be in contact with the subsurface, constitute major motivations for further exploration of the astrobiological potential of this ocean world [29]. On Enceladus, the accessibility of the contents of its subsurface ocean and hydrothermal system is an unprecedented opportunity to determine its abiotic or prebiotic potential while its comet-like composition raises new questions about the evolution of the Saturnian system and the Solar System in general. In the over two decades since the launch of the Cassini-Huygens mission in 1997, there have been great technological advancements in instrumentation that would enable answering key questions that still remain about the Saturnian ocean worlds.

We therefore propose a Voyage 2050 theme of ocean worlds evolution and habitability with a focus on Enceladus and Titan in the Saturn system. Building on the heritage of Cassini-Huygens, future exploration of Enceladus and Titan should be dedicated to investigating the unique properties and the habitability potential of these ocean worlds. The proposed baseline is for a large mission (class L) and consists of multiple flybys using a solar-electric powered spacecraft in orbit around Saturn. The proposed mission would have a focused payload that would provide high-resolution mass spectrometry of the plume emanating from Enceladus' south polar terrain and of Titan's upper atmosphere. High-resolution IR imaging would be performed of the plume and the source fractures on Enceladus' south polar terrain (SPT), and would detail Titan's geomorphology at 50-100 m resolution at minimum. In addition, radio science measurements would provide constraints on the ice shell structure and the properties of the internal ocean of Enceladus and constrain higher degree gravity field components of Titan. The baseline mission is based on the Explorer of Enceladus and Titan $\left(E^{2} \mathrm{~T}\right)$ concepts proposed as a medium-class mission led by ESA in collaboration with NASA in response to ESA's M5 Call [102], along with several other previous 
proposals (e.g., TSSM, [27]; TIME, [155]; JET, [149]) and will complement the information provided by Cassini-Huygens, as well as the results of the newlyselected NASA Dragonfly mission [79].

The baseline mission can address key scientific questions regarding extraterrestrial habitability, abiotic or prebiotic chemistry, the emergence of life, and the origin and evolution of ocean worlds. Optional elements include 1) an in-situ sea-probe to investigate one of Titan's northern seas as well as the lower atmosphere and 2) an ice penetrating radar (IPR) to perform radar sounding of the subsurface of Titan and Enceladus during flybys. The in-situ sea-probe would open up new vistas regarding Titan's seas and lakes, the hydrological system and the possibility of prebiotic or biotic components within Titan's seas, complementing the equatorial investigations of NASA's Dragonfly, while the IPR would reveal subsurface structures and processes of Titan and Enceladus' SPT. While the baseline mission is conceived as a multiple flyby mission it can also include a final orbiter phase around Titan. The joint exploration of these two fascinating objects would potentially be performed with international collaboration and will allow us to better understand the origin of their organicrich, liquid water habitable environment and will give access to planetary processes that have long been thought unique to the Earth. Finally, joint exploration of these ocean worlds would complement NASA's Dragonfly mission to Titan, which while unprecedented is only regional in scope exploring a low-latitude impact crater site (Selk impact crater). Thus, local observations of Enceladus' south pole, global observations of Titan, and possible in-situ exploration of a northern sea are important science goals that remain to be addressed by a future mission to the Saturn system.

\subsection{Titan: An organic-rich evolving world}

Shrouded by a dense atmosphere of nitrogen, methane, hydrogen, and haze products, Titan, Saturn's largest satellite, was once thought to host a global ocean of methane and ethane on its surface [80]. Data from the Cassini-Huygens mission uncovered a fascinating Earth-like world beneath the haze with dunes (e.g., [74]), lakes and seas [154], networks of rivers and canyons [123, 143, 163], and mountains [99, 131] and impact structures $[73,110,144,176]$ within an alien landscape composed of organics and waterice. Titan's dense, extensive atmosphere is primarily composed of nitrogen (97\%) and methane (1.4\%) (e.g., [9]), and a long suite of organic compounds resulting from multifaceted photochemistry which occurs in the upper atmosphere down to the surface (e.g., $[9,45,66,173])$. Titan's organic-rich dense atmosphere has provided a rich field of study with multiple models investigating the origin of its nitrogen atmosphere (e.g., [94, 105]), the persistence of atmospheric methane despite methane escape, and the distribution of its atmospheric components. The organics detected by the Cassini mission in Titan's atmosphere have provided tantalizing hints of the prebiotic potential of Titan's atmospheric aerosols [164]. For example, a compelling find by Cassini for abiotic or prebiotic species is the discovery of complex large nitrogen-bearing organic molecules in Titan's upper atmosphere [23, 173]. Stevenson et al. [153] suggest that membranes formed from atmospheric nitriles such as acrylonitrile could provide Titan analogues of terrestrial lipids, a component essential to life on Earth.

Since methane is close to its triple point on Titan, it gives rise to an alkanological cycle analogous to the terrestrial hydrological cycle, characterized by cloud activity, 
precipitation, river networks, lakes and seas covering a large fraction of the northern terrain (Fig. 1) (e.g., [50, 97, 154, 163]). Titan is the only extraterrestrial planetary body with long-standing liquid on its surface, albeit hydrocarbons instead of water, likely fed by a combination of precipitation, surface runoff and subsurface alkanofers (hydrocarbon equivalent of aquifers) in the icy shell [50]. Recent work has shown that the surfaces of Titan's northern lakes and seas are on the same equipotential surface confirming the presence of subsurface alkanofers [51,89]. Titan's seas and larger lakes are typically broad edge depressions while many small lakes present as sharp edge depressions often with raised ramparts [11] and some surrounded with rampart-like structures [147]. Observations of water-ice poor 5- $\mu \mathrm{m}$ bright material surrounding Titan's northern lakes and seas may be evaporite deposits [6]; though they are also found in the largest areal concentration in equatorial regions and if they do represent evaporites, suggest previous equatorial seas [85]. Experimental work in Titan conditions is attempting to reveal compounds that could form evaporites on Titan and their prebiotic and biotic potential [18, 19].

The presence of radiogenic noble gases in the atmosphere indicates some communication between the surface and the subsurface and is suggestive of water-rock interactions and methane outgassing processes [161], possibly associated with cryovolcanic activity $[71,73]$. The detection of a salty ocean at depth estimated between $50 \mathrm{~km}$ and $80 \mathrm{~km}$ beneath the surface $[8,62,101,148]$ and the possible communication between this ocean and the organic-rich surface opens up exciting astrobiological perspectives. While Cassini has provided tantalizing views of the surface with its lakes and seas, dunes, equatorial mountains, impact craters, and possible cryo-volcanoes, its low resolutions make it difficult to identify morphological features, to quantify geological processes and relationships between different geological units and monitor changes due to geologic or atmospheric activity. Determining the level of geological activity on Titan is crucial in understanding its evolution and whether this ocean world could support abiotic or prebiotic activity.

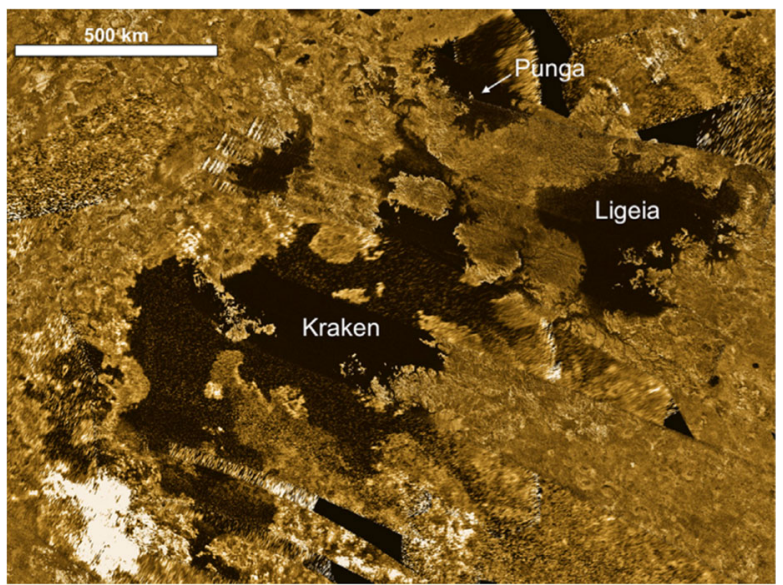

Fig. 1 Cassini SAR mosaic images of the north polar region showing Kraken, Ligeia, and Punga Maria. Black-yellow color map was applied to the single band data (from [100]) 


\subsection{Enceladus: An active aqueous environment}

The discovery in 2005 of a plume of multiple jets emanating from Enceladus' south polar terrain (SPT) is one of the major highlights of the Cassini-Huygens mission (Fig. 2) $[35,84,124,150]$. Despite its small size (10 times smaller than Titan), Enceladus is the most active moon of the Saturnian system. Although geyser-like plumes have been observed on Triton [145] and more recently transient water vapor activity around Europa has been reported [134, 135], Enceladus is the only one proven to have current endogenic activity. Approximately 100 jets [125] form a huge plume of vapor and ice grains above Enceladus' south polar terrain and are associated with abnormally elevated heat flow along tectonic ridges, called 'tiger stripes'. Enceladus' endogenic activity and gravity measurements indicate that it is a differentiated body providing clues to its formation and evolution [63]. Gravity, topography and libration measurements demonstrate the presence of a global subsurface ocean $[20,63,93,157]$. Analysis of the gravity data showed that Enceladus' ice shell thickness above the subsurface ocean is likely $30-40 \mathrm{~km}$, from the south pole up to $50^{\circ} \mathrm{S}$ latitude [63] while libration data suggest a mean thickness of 21-26 km [157]; however recent models have shown that the variable ice shell thickness in Enceladus' south pole can be as little as $5 \mathrm{~km}[20,21]$. This variable ice shell thickness could be the result of heat flux variation along the ice-ocean interface due to true polar wander [156].

Postberg et al. [127] and Porco et al. [125] have shown that most of the plume material is likely not from the upper brittle layer of the ice shell but from a subsurface liquid water reservoir beneath the icy shell. Libration measurements finally confirmed the presence of a global ocean [157]. Sampling of the plume by Cassini's instruments revealed the presence of water vapor, ice grains rich in sodium and potassium salts [128], gas and solid phase organics [126, 129, 174]. The jet sources are connected to a subsurface salt-water reservoir that is probably alkaline in nature and the site of possible hydrothermal water-rock interactions [40, 57, 58, 124, 125, 127, 128, 172, 174].

The co-existence of organic compounds, salts, liquid water, and energy sources on this small moon provides all the necessary ingredients for the emergence of life by chemoautotrophic pathways [91] - a generally held model for the origin of life on Earth in deep sea vents, such as the Lost City hydrothermal field located in the Mid-Atlantic Ridge. The eruption activity of Enceladus offers a unique possibility to sample fresh

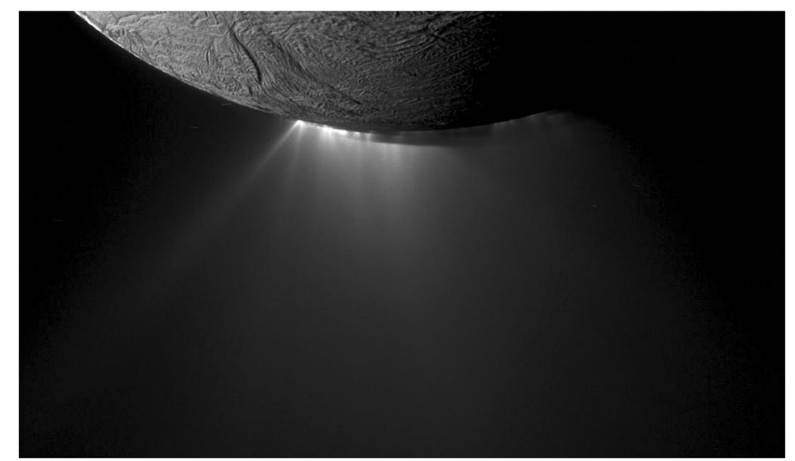

Fig. 2 Plume emanating from multiple jets in Enceladus' south polar terrain. Image credit: NASA/JPLCaltech 
material emerging from subsurface liquid water and to understand how exchange processes with the interior control surface activity. It provides us with an opportunity to in situ study phenomena that have been important in the past on Earth and throughout the outer Solar System.

\section{Science case after the Cassini-Huygens mission}

While Cassini-Huygens and its extended missions have revealed much about Enceladus and Titan [36, 84], the spacecraft was not equipped to search for life or constrain the evolution of these ocean worlds and many open questions remain. In situ measurements by Cassini at Enceladus and Titan revealed a wealth of chemical complexity of neutral and positively charged molecules. However, analysis was restricted by mass spectroscopic instruments, which were limited by their low sensitivity, mass range, and resolution and subsequent inability to resolve high-mass isobaric molecular species, neutral and positive ions. For example, in Enceladus' vapor plume an unidentified species with a mass-tocharge $(\mathrm{m} / \mathrm{z})$ ratio of 28 , which is thought to be either $\mathrm{CO}, \mathrm{N}_{2}, \mathrm{C}_{2} \mathrm{H}_{4}$ or a combination of these compounds was detected. Determining the abundance ratio between these different species is essential to constrain the origin of volatiles on Enceladus and to assess whether they were reprocessed internally. The evidence of high temperature hydrothermal activity [59] within Enceladus' subsurface ocean provides strong incentive to test the plume for prebiotic and biotic signatures using high-resolution spectrometers. Further, putative exothermic water-rock interactions on Enceladus could be further constrained by quantifying $\mathrm{H}_{2}$ in the plume. On Titan, higher resolution spectroscopic instruments would enable better constraints on complex organic processes and components occurring in Titan's atmosphere, particularly those with prebiotic and biotic potential.

The geology and morphology of both Titan and Enceladus has been revealed by Cassini Visual and Infrared Mapping spectrometer (VIMS), Imaging Science Subsystem (ISS), and RADAR SAR imagery but only at low to moderate resolutions. Additionally, imaging of the surface was also constrained on Titan by scattering of atmospheric aerosols and absorption that limited signal-to-noise. A future mission to Titan can provide images in the mid-IR range at or around $5 \mu \mathrm{m}$ since images at these wavelengths are subject to minimal scattering $[7,146]$ enabling diffraction limited images that are extremely sensitive to composition $[5,22]$ with spatial resolutions an order of magnitude better than Cassini observations [5, 22, 146]. A high-resolution map would enable a vastly improved investigation of Titan's geology, hydrology, and composition variability and would enable the detection of morphology not evident from Cassini data, quantify geological processes and relationships between different geological units and examine alterations due to geologic, atmospheric or seasonal activity. Recently an ice-rich linear feature of bedrock, covering $40 \%$ of Titan's circumference was discovered using statistical analysis of 13,000 Cassini VIMS images [43]; it is likely many features with weaker spectral signatures remain to be discovered. High-resolution imaging of Enceladus' SPT will provide new detail of the tectonically active surface, constrain characteristics of the hydrothermal system by investigating the composition and kinematics of Enceladus' jets and plumes. Further IR imaging will view thermal emission from Enceladus' hot spots and constrain the presence of anomalous heat signatures in the SPT [69], at resolutions comparable to ISS observations of the SPT. 
Gravity field measurements are powerful tools to constrain the interior structure and to assess mass anomalies, providing information on the internal dynamics and evolution. Gravity measurements of Enceladus' south pole can be used to find a local solution of the SPT gravity field and its time-variation (using along-track data) rather than a global solution. In the south polar region, we expect a larger time-variation of the gravity field with respect to the global solution of the time variation of the gravity field due to the fact that the ice shell thickness is expected to be locally thin at the SPT. A radio science experiment that will determine the local solution of the gravity field of Enceladus at the SPT will allow the determination of the thickness variation at the south polar regions and constraints on the mechanical properties (viscosity) of the ice overlying an outer ice shell. The expected tidal deformation is characterized by a pattern more complex than the standard degree-two pattern, with a strong amplification of the tidal fluctuation in the SPT. Should a final Titan orbiter phase be included in the baseline mission, higher degrees of gravity coefficients, up to at least degrees twelve could be obtained as well as an estimation of the real and imaginary parts of Titan's Love number, $\mathrm{k}_{2}$, with an accuracy of 0.0001 [165]. The characterization of the global gravity field of Titan and/or Enceladus might also be significantly improved through a pair of companion small satellites, to be released by the mothership around either moons. This element may complement the science observations of the larger spacecraft, through a combination of Satellite-to-Satellite Tracking (SST) between two smallsats or between one smallsat and the mothership. Preliminary simulations have shown that in just three months this technique would allow to estimate the static gravity field up to at least degree thirteen (for Titan) and degree twenty (for Enceladus), while the real and imaginary part of $\mathrm{k}_{2}$ can reach an accuracy of about 0.08 for Titan and 0.002 for Enceladus $[166,167]$. This optional element may be studied in parallel to the mission options 1) sea probe (lander) and 2) ice penetrating radar listed in the Introduction and discussed in more detail in Sections 3.2, 3.3 and 5.

The subsurface processes and structures of both Titan and Enceladus can be further investigated with an ice penetrating radar (IPR), which uses microwaves to penetrate through the surface to examine subsurface characteristics. Structural, thermal, and compositional profiles of subsurface structures and thickness of the regolith layer can be used to characterize the surface and subsurface structures and determine their correlation to each other. Further determination of the ice-ocean interface at Enceladus' SPT and the brittle-ductile interface within Titan's ice shell can constrain evolutionary and thermal processes. Radar sounding instruments have been used in multiple space missions on Mars and the Moon (e.g., [53, 119, 122, 141]) and will be used to examine Europa and Ganymede in the Jupiter system in ESA's upcoming JUICE mission [14, 15]. The upcoming NASA mission, Europa Clipper, will radar sound Europa during a series of multiple flybys while in orbit around Jupiter [12].

While Cassini has provided stunning imagery of Titan's lakes and seas (e.g. [154]) and VIMS and RADAR data have been used to constrain their composition and bathymetry $[13,73,88]$, open questions regarding their formation, particularly smaller sharp edge depression lakes, the extent of subsurface communication, composition of the lakes and seas and the evaporites that often surround them as well as paleolakes in the south pole and possible presence of lakes or empty lake basins outside the polar regions still remain (e.g. [103, 117]). The combination of high resolution remote sensing and in situ measurements can answer many questions. In addition, in situ 
studies of one of Titan's seas would complement data obtained by the Dragonfly mission, which was selected by NASA in 2019 as part of its New Frontiers program as an upcoming mission to be launched in 2026 and arrive at Titan in 2034. The Dragonfly mission while unprecedented is only regional in scope exploring the lowlatitude Selk impact crater region with a flying rotorcraft drone [79]. Thus in situ exploration of a northern sea and global observations of Titan are important science goals that remain to be addressed by a future mission to the Saturn system.

Science goals to be resolved by a future baseline multiple flyby mission to Titan and Enceladus, based on the $\mathrm{E}^{2} \mathrm{~T}$ mission proposed for ESA M5 study [102] are shown in Table 1. Additional science goals that can be investigated with the option \#1 of in situ exploration of a northern sea and/or the option \#2 of radar sounding of the surface of Titan and Enceladus SPT during multiple flybys or Titan's orbiter are described in Table 2 and Table 3 respectively.

\section{Missions scenarios}

\subsection{Baseline mission scenario}

The proposed baseline mission concept consists of a solar-electric powered spacecraft performing multiple flybys of Titan and Enceladus while in orbit around Saturn. The proposed baseline mission is based on the Explorer of Enceladus and Titan $\left(\mathrm{E}^{2} \mathrm{~T}\right)$ proposed as a medium-class mission led by ESA in collaboration with NASA in response to ESA's M5 Call [102]. The proposed baseline mission concept for this White Paper is for a large class ESA mission (class L). The evaluated cost from ESA review for $\mathrm{E}^{2} \mathrm{~T}$ is $950 \mathrm{M} €$ that fit in a large mission budget constraint.

The baseline payload would consist of three scientific instruments: two time-offlight mass spectrometers and a high-resolution infrared camera, while the telecommunication system would be utilized to perform gravity science. The baseline interplanetary transfer, cruise and flyby phases are all based on a proposed launch in 2029-2030 and therefore are included only as example trajectories. After the launch, the spacecraft will transfer from geosynchronous transfer orbit (GTO) to a hyperbolic escape trajectory and would pursue a gravity assist flyby of the Earth to help propel itself to the

Table 1 Science goals of baseline mission

Science summary

\begin{tabular}{ll} 
Science goals & Science objectives \\
\hline $\begin{array}{l}\text { Origin and evolution of volatile-rich ocean } \\
\text { worlds, Enceladus and Titan }\end{array}$ & $\begin{array}{c}\text { - Are Enceladus' volatile compounds primordial or have they } \\
\text { been re-processed and if so, to what extent? } \\
\text { - What is the history and extent of volatile exchange on Titan? } \\
\text { - How has Titan's organic-rich surface evolved? }\end{array}$ \\
$\begin{array}{c}\text { Habitability and potential for life of ocean } \\
\text { worlds, Enceladus and Titan }\end{array}$ & $\begin{array}{c}\text { Is Enceladus' aqueous interior an environment favorable to the } \\
\text { emergence of life? } \\
\text { - To what level of complexity has prebiotic chemistry evolved in } \\
\text { the Titan system? }\end{array}$
\end{tabular}


Table 2 Science goals of optional sea probe (lander) element

Science summary

\begin{tabular}{ll} 
Science goals & Science objectives \\
\hline $\begin{array}{l}\text { Origin and evolution of Titan's lakes } \\
\text { and seas }\end{array}$ & $\begin{array}{r}\text { - How does the hydrological cycle work, and what is the role of the } \\
\text { lakes and seas? How have the seas and lakes evolved over time } \\
\text { (e.g., shorelines)? } \\
\text { - Constrain the depth of a Titan sea } \\
\text { - What is the lower atmosphere over the sea? } \\
\text { - Constrain sea-atmosphere interactions } \\
\text { - What is the composition of the seas and lakes?- Are there any } \\
\text { prebiotic or biotic signature compositions?- What is the } \\
\text { composition of evaporites and what is their relation to the lakes and } \\
\text { Titan's lakes and seas }\end{array}$ \\
&
\end{tabular}

Saturn system. The cruise phase from Earth to Saturn would be 6 years long. After the arrival in the Saturn system, the mission is divided in a first Enceladus science phase and in a second Titan science phase. The spacecraft should perform at least 6 flybys of Enceladus above the south polar terrain (SPT) and at least 17 flybys of Titan. To prevent contamination of Enceladus science by Titan's organics, $\mathrm{E}^{2} \mathrm{~T}$ spacecraft will perform close flybys of Enceladus at the beginning of the tour (Enceladus science phase); distant flybys of Titan will be performed during the initial tour phase.

After the main Enceladus phase, close flybys of Titan with atmospheric sampling will be performed (Titan science phase). During the Titan science phase, the spacecraft will provide in situ sampling of the upper atmosphere at a minimum altitude from Titan surface as low as $900 \mathrm{~km}$ using mass spectrometers. At the closest approach the velocity of the spacecraft with respect to Titan's surface will be $\sim 7 \mathrm{~km} / \mathrm{s}$. Imaging data would be collected during inbound and outbound segments of each flyby. The duration of the tour from its arrival in the Saturn system to the end of the 17-flyby Titan phase is about 3.5 years. Figure 3 shows a proposed interplanetary transfer to Saturn and Fig. 4 shows a proposed sample tour. Both Figs. 3 and 4 are based on a proposed E2T launch of 2029-2030 [102]. Figure 5 shows the proposed configuration of the spacecraft for the $\mathrm{E}^{2} \mathrm{~T}$ project. While the baseline mission is conceived as a multiple flyby mission it

Table 3 Science goals of optional Ice Penetrating Radar (IPR) element

Science summary

Science goals $\quad$ Science objectives

Interior structure and processes of Enceladus and Titan
- What is the thickness of the surface organic material layer on Titan?

- How does ice thickness vary in Enceladus' south polar terrain?

- Constrain brittle-ductile transition within Titan's ice shell

- How do the surface and subsurface features correlate on Titan and Enceladus?

- Constrain the extent of Enceladus' ocean at SPT

- Constrain anomalous thermal emission beneath SPT

- What is the extent of surface and subsurface communication especially in the polar regions of both Titan and Enceladus? 
can also include a final orbiter phase around Titan similar to the final orbiter phase of the JUICE (JUpiter ICy moons Explorer) spacecraft around Ganymede in the upcoming ESA JUICE mission.

\subsection{Option 1: Titan Sea lander}

The spacecraft will carry a scientific payload consisting of remote sensing instruments and experiments aforementioned while if Option \#1 is utilized the spacecraft will also carry an Entry, Descent and Landing (EDL) module containing a sea lander equipped with an instrument suite capable of carrying out in situ measurements of one of Titan's north polar seas. Figure 6 shows a proposed sea lander and entry vehicle. During the descent, the probe will make in situ measurement of the atmosphere. Once a successful splashdown has been achieved, the sea probe will be taking measurements sampling both the liquid of the seas and the atmosphere above. Previous analysis for a mission that considered the exploration of Titan using an orbiter, a lake-probe, and a balloon demonstrated the feasibility of such mission (the Titan Saturn System Mission Study TSSM, [28]) as did the study of the Titan Mare Explorer (TiME) [155] which was a lake lander only mission to in-situ investigate one of the large north polar mare on Titan. In addition, Mitri et al. [101] presented the science case for the exploration of Titan and one of its seas with an orbiter and a lake probe. If Option \#2 is utilized, the spacecraft will carry a nadir-looking ice penetrating radar sounder (IPR).

The sea lander will sample Titan's atmosphere obtaining temperature, wind, humidity, and composition profiles during its descent. Once the sea lander is in the Titan sea, it will make a number of measurements including bulk and trace composition of the sea

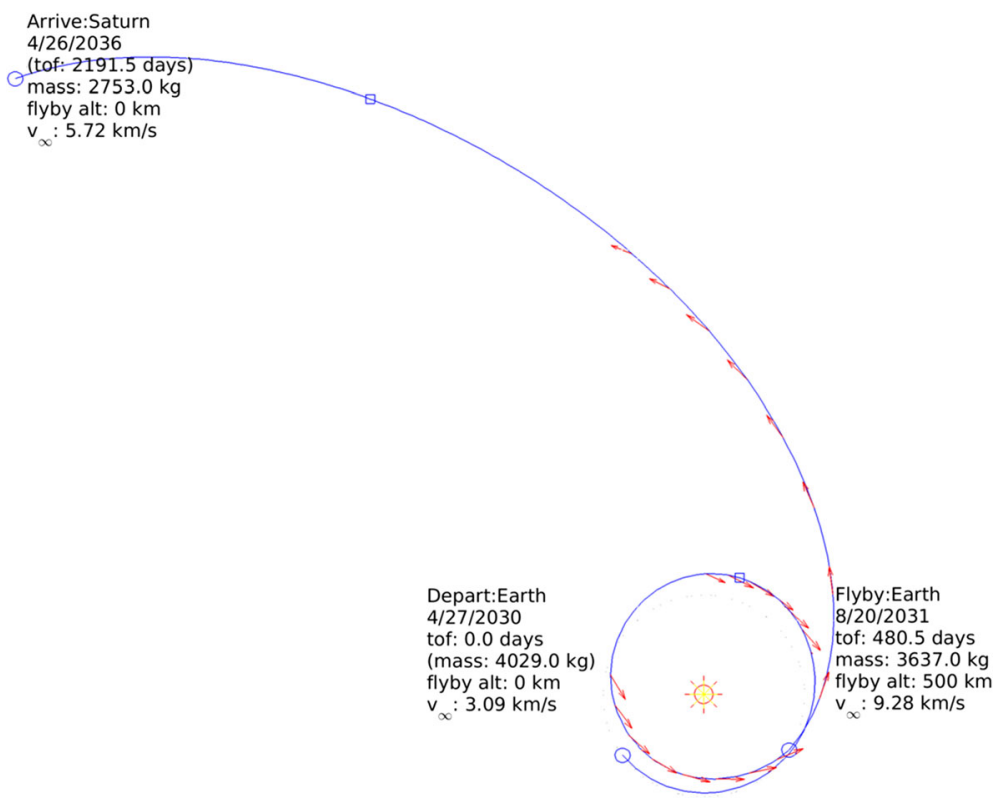

Fig. 3 Example interplanetary transfer to Saturn studied for $\mathrm{E}^{2} \mathrm{~T}$ proposal based on a proposed launch in 2029-2030 [102]. Red arrows indicate electric propulsion thrust. Such a scenario could be used to design a future transfer trajectory 


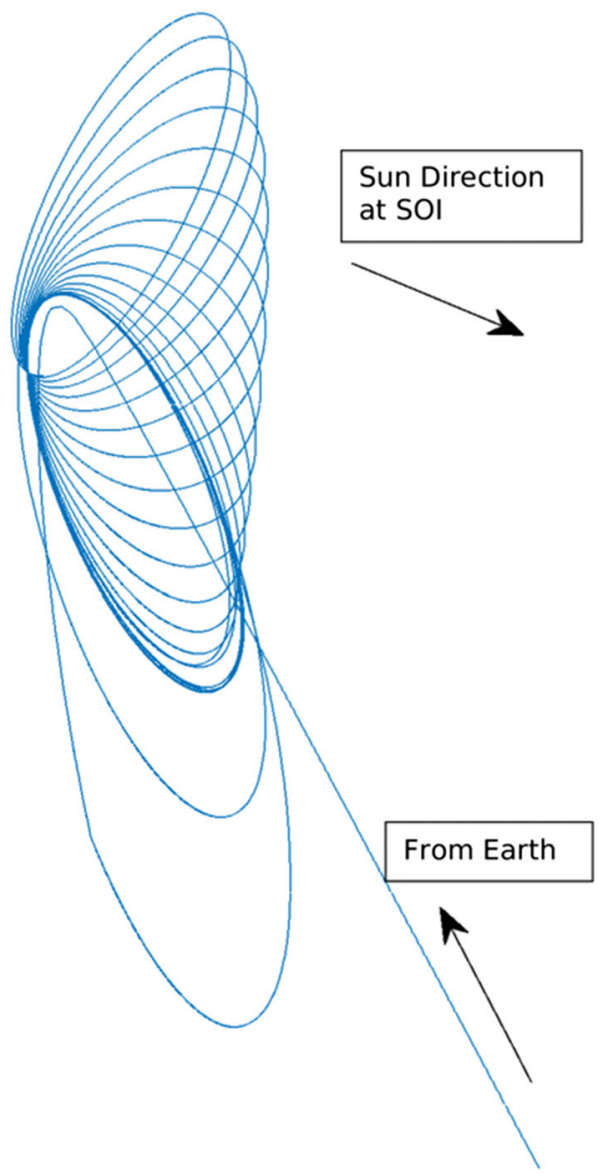

Fig. 4 Inertial representation of a sample tour based on a proposed 2029-2030 launch with two period- and inclination-management Titan flybys followed by a science phase with 6 Enceladus flybys and 17 Titan flybys [102]

and lower atmosphere, and bathymetric and shoreline profiles; additionally, the shoreline of the sea can be imaged during the descent. A possible instrument suite utilized by a sea lander with associated science goals and measurements is shown in Table 4 [101].

The sea lander will relay data to the spacecraft, which will serve as the communications link between the probe and Earth. Direct-to-Earth (DTE) communication of the sea lander is a possible complementary communication method. Lorenz and Newman [75] have found that the seasonal geometry at Titan's north pole allows DTE from the seas until 2026 and after 2040. Given the opacity of Titan's atmosphere, the use of a solar powered generator for the sea-probe is infeasible if its operations need to last more than a few hours. The sea lander portion of the proposed mission will be short-lived due to technical constraints. Current technology dictates that the use of batteries will only provide power to the sea lander on the order of hours; though this technology will likely improve. The sea lander will not have propulsion capabilities rather it will be propelled around the lake by winds and possible tides; Lorenz and Mann [76] have studied the wind and wave conditions that a floating Titan sea lander might encounter. Testing of a 


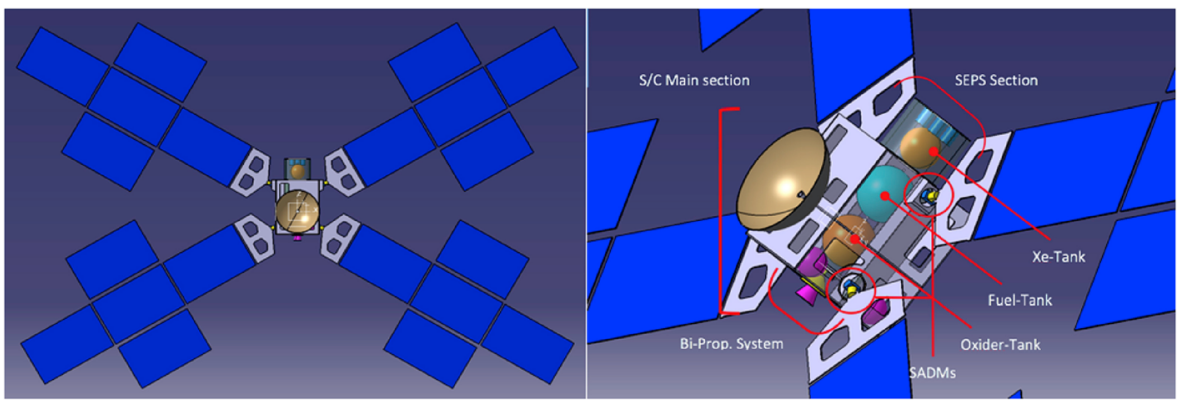

Fig. 5 Proposed configuration of the spacecraft for the $\mathrm{E}^{2} \mathrm{~T}$ project. Top panel shows an enlarged view of the spacecraft and below panel shows a close-up view of the spacecraft [102]

scale model of the proposed Titan Mare Explorer sea lander capsule has revealed important data regarding potential science operations and lander-lake dynamics [77, 78]. Recent work proposes that a sea-lander could possibly not only float but also be able to propel itself utilizing mechanical tensegrity structures [38]. The use of a radioisotopic power generator for the sea probe could be requested to be the technology used, which could significantly reduce the amount of plutonium fuel. The Advanced Stirling Radioisotopic Generator (ASRG), based on Stirling power conversion technology, offers a fourfold reduction in the amount of plutonium fuel compared to radioisotope thermal generators (RTG) used in previous interplanetary missions [155]; while NASA has ended funding for in-flight development of ASRG technology in 2013 due to budget cuts, research continues on this technology and other radioisotope power systems in NASA [120]. Additionally, the development of radioisotopic power using Americium ( $\left.{ }^{241} \mathrm{Am}\right)$ currently being developed by ESA since 2008 is another possible option [4].
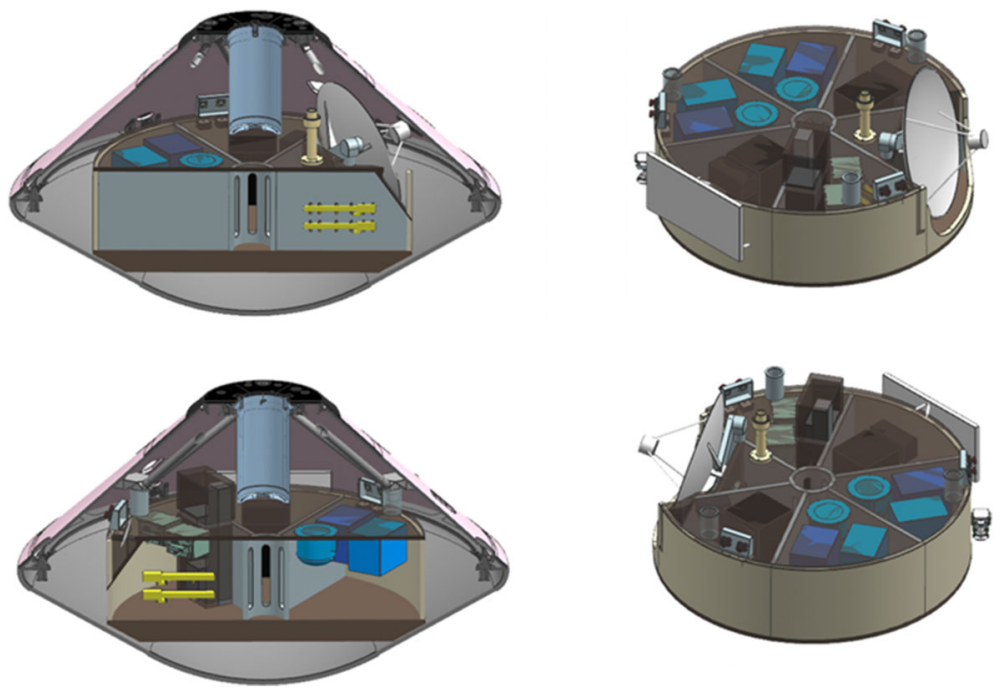

Fig. 6 Examples of a sea lander and entry vehicle. The left-hand panel shows front and back views of the sea lander inside the entry vehicle while the right-hand panel shows the sea lander only. Credit: JPL 
Table 4 Science objectives, measurements, and proposed techniques for option 1, the sea probe/lander [101]

\begin{tabular}{|c|c|c|c|}
\hline \multicolumn{2}{|c|}{ Science objectives } & \multirow{2}{*}{$\begin{array}{l}\text { Measurements } \\
\text { Sea composition, including low } \\
\text { and high mass hydrocarbons, } \\
\text { noble gases, and carbon } \\
\text { isotopes }\end{array}$} & \multirow{2}{*}{$\begin{array}{l}\begin{array}{l}\text { Approaches and } \\
\text { requirements }\end{array} \\
\text { Mass spectrometry } \\
\text { Low atmosphere physical } \\
\text { properties package } \\
\text { (temperature sensor, } \\
\text { barometer, } \\
\text { anemometer) }\end{array}$} \\
\hline Lakes/seas & $\begin{array}{l}\text { Characterize one of Titan's } \\
\text { northern seas and its } \\
\text { chemical composition } \\
\text { (astrobiological potential) }\end{array}$ & & \\
\hline & & $\begin{array}{l}\text { Exchange processes at the } \\
\text { sea-air interface to help con- } \\
\text { strain the methane cycle }\end{array}$ & $\begin{array}{l}\text { Low-atmosphere physical } \\
\text { properties package } \\
\text { (temperature sensor, } \\
\text { barometer, } \\
\text { anemometer) }\end{array}$ \\
\hline & & $\begin{array}{l}\text { Presence and nature of waves } \\
\text { and currents }\end{array}$ & $\begin{array}{l}\text { Physical properties } \\
\text { package } \\
\text { Surface Imaging }(\sim 250 \\
\quad \mu \mathrm{rad} / \text { pixel })\end{array}$ \\
\hline & & $\begin{array}{l}\text { Properties of sea liquids } \\
\text { including turbidity and } \\
\text { dielectric constant }\end{array}$ & $\begin{array}{l}\text { Sea physical properties } \\
\text { package (turbidity and } \\
\text { dielectric constant } \\
\text { measurements) }\end{array}$ \\
\hline & & $\begin{array}{l}\text { Sea depths to constrain basin } \\
\text { shape and sea volume }\end{array}$ & Sonar \\
\hline & & $\begin{array}{l}\text { Shoreline characteristics, } \\
\text { including evidence for past }\end{array}$ & $\begin{array}{l}\text { Surface Imaging }(\sim 250 \\
\quad \mu \mathrm{rad} / \mathrm{pixel})\end{array}$ \\
\hline & & & $\begin{array}{l}\text { Surface Imaging }(\sim 250 \\
\quad \mu \mathrm{rad} / \mathrm{pixel})\end{array}$ \\
\hline \multirow[t]{2}{*}{ Atmosphere } & $\begin{array}{l}\text { Determine Temperature, } \\
\text { Pressure, composition, } \\
\text { evaporation rate, and } \\
\text { physical properties that } \\
\text { characterize lake and } \\
\text { atmosphere interactions }\end{array}$ & $\begin{array}{l}\text { Determine Temperature, } \\
\text { Pressure, composition, } \\
\text { evaporation rate, and } \\
\text { physical properties that } \\
\text { characterize lake and } \\
\text { atmosphere interactions }\end{array}$ & $\begin{array}{l}\text { Mass spectrometry } \\
\text { Physical properties } \\
\text { package }\end{array}$ \\
\hline & $\begin{array}{l}\text { Characterize the atmospheric } \\
\text { composition during probe } \\
\text { descent }\end{array}$ & Determine the composition & Mass spectrometry \\
\hline
\end{tabular}

\subsection{Option 2: Radar sounder}

The ice penetrating radar (IPR), following the heritage of JUICE RIME and Europa Clipper REASON, would be capable of both shallow and deep sounding to characterize the subsurface with a depth of $9 \mathrm{~km}$ and $\sim 30 \mathrm{~m}$ vertical resolution at minimum. Both RIME and REASON are to operate at a high frequency (HF) band with a centerfrequency of $9 \mathrm{MHz}$ and possess bandwidths between $1 \mathrm{MHz}$ and $3 \mathrm{MHz}$ while REASON operates at an additional VHF frequency with a center frequency of $60 \mathrm{MHz}[14,44]$. An IPR can characterize structural, compositional, and thermal variations occurring in the subsurface providing data that can correlate surface and subsurface features and processes, deformation in the upper ice shell, as well as global 
and local surface age. In addition, an IPR can also investigate the ice-ocean interface at Enceladus' SPT and brittle-ductile transition on Titan constraining the thickness and thermal evolution of the ice shells. An additional option for radar architecture could be a multi-mode radar design suitable for both sounding and imaging to be operated in two modes: a vertical sounder mode with similar capabilities as described above though with different architecture, and a Synthetic Aperture Radar (SAR) imaging mode, similar to Cassini [37], but with a higher resolution at tens of meters. The additional SAR mode could be used for high-resolution imaging of the surface, complementing the IR imaging, as well as for creating three-dimensional high-resolution bathymetric maps of Titan seas and lakes and could permit investigation of any possible compositional variation in space and time of the hydrocarbon liquid and/or sea floor properties.

\section{Science case for the baseline mission scenario}

In this section we discuss the science goals and themes for the proposed baseline mission based on the $\mathrm{E}^{2} \mathrm{~T}$ mission submitted to ESA in response to the M5 Call [102]. Discussion of the science themes of the proposed mission options is discussed in Section 5.

\subsection{Origin and evolution of volatile-rich ocean worlds, Enceladus and titan}

The origin of volatiles currently present on Titan and Enceladus is still being debated. New data are needed to determine if the volatile inventory is primordial, originating in the solar nebula or in the Saturnian subnebula where it was possibly altered during the accretion process or if the volatile inventory was produced in some secondary manner that is still being debated (e.g., [3]). How photochemical processes on Titan and aqueous alteration on Enceladus have affected the initial volatile inventory remains unknown. Given that a late accretion scenario may explain the mass distribution and ice/rock ratio of the mid-sized moons in the Saturn system, Enceladus may have formed less than 1 billion years ago, while Titan may have accreted early. This may have resulted in significant differences in their initial volatile inventory and their subsequent evolution.

By combining in situ chemical analysis of Titan's atmosphere and Enceladus' plume with observations of Enceladus' plume dynamics and Titan's surface geology, a future mission can provide constraints on how these ocean worlds acquired their initial volatile inventory and how it was subsequently modified during their evolution [84]; these investigations can improve our understanding of the nature of Saturn subnebula formation conditions and its subsequent evolution as well as the conditions of the early solar nebula, the nature of cometary and giant impacts, all of which might also help to predict the physical and chemical properties of terrestrial planets and exoplanets beyond the Solar System.

\subsection{Chemical constraints on the origin and evolution of titan and Enceladus}

The origin and evolution of Titan's methane still needs to be constrained. Whether Titan's methane is primordial likely through water-rock interactions in Titan's interior during its accretionary phase [3] or else delivered to Titan during its formation processes [107] or by cometary impacts [42, 177] is a key open question. On Titan, the Huygens probe detected a small argon abundance $\left({ }^{36} \mathrm{Ar}\right)$ and a tentative amount of 
neon $\left({ }^{22} \mathrm{Ne}\right)$ in its atmosphere $[113,155]$, but was unable to detect the corresponding abundance of xenon and krypton. The presence of ${ }^{22} \mathrm{Ne}$ (with ${ }^{36} \mathrm{Ar} / 22 \mathrm{Ne} \sim 1$ ) was unexpected as neon is not expected to be present in any significant amounts in protosolar ices $[113,155]$ and may indicate water-rock interactions and outgassing processes [161]. The non-detection of xenon and krypton supports the idea that Titan's methane was generated by serpentinization of primordial carbon monoxide and carbon dioxide delivered by volatile depleted planetesimals originating from within Saturn's subnebula (e.g., [3]). Xenon and krypton would both have to be sequestered from the atmosphere to support a primordial methane source. While xenon is soluble in liquid hydrocarbons (solubility of $10^{-3}$ at $95 \mathrm{~K}$ ) and could potentially be sequestered into liquid reservoirs, argon and krypton cannot [25]. Therefore, the absence of measurable atmospheric krypton requires either sequestration into non-liquid surface deposits, such as clathrates [108], or depletion in the noble gas concentration of the planetesimals [121]. Unlike the Cassini Ion and Neutral Mass Spectrometer (INMS), which was developed in the 1990s, current and future spectrometers have the mass range and sensitivity to accurately measure xenon. Measurement of the abundance of noble gases in the upper atmosphere of Titan can discriminate between crustal carbon sequestration and carbon delivery via depleted planetesimals.

The longevity of methane in Titan's atmosphere is still a mystery. The value of ${ }^{12} \mathrm{C} /$ ${ }^{13} \mathrm{C}$ in Titan's atmosphere has been used to conclude that methane outgassed $\sim 10^{7}$ years ago [171] and is being lost via photolysis and atmospheric escape [170]. It is an open question whether the current methane rich atmosphere is a unique event, whether it is in a steady state where methane destruction and replenishment are in balance [67], or else is a unique transient event and is in a non-steady state where methane is being actively depleted or replenished. Indeed, the possibility that Titan did not always possess a methane rich atmosphere seems to be supported by the fact that the amount of ethane on Titan's surface should be larger than the present inventory (this is further discussed in the geological processes section below); though Wilson and Atreya [175] contend that missing surface deposits may simply be reburied into Titan's crust and Mousis and Schmitt [106] have shown that it is possible for liquid ethane to react with a water-ice and methane-clathrate crust to create ethane clathrates and release methane. Nixon et al. [116], however, favor a model in which methane is not being replenished and suggest atmospheric methane duration is likely between $300 \mathrm{Ma}$ and $600 \mathrm{Ma}$ given that Hörst et al. [54] demonstrated that $300 \mathrm{Ma}$ is necessary to create Titan's current CO inventory and recent surface age estimates based on cratering [110]. Mandt et al. [87] suggests that methane's presence in the atmosphere, assumed here to be due to outgassing, has an upper limit of $470 \mathrm{Ma}$ or else up to $940 \mathrm{Ma}$ if the presumed methane outgassing rate was large enough to overcome ${ }^{12} \mathrm{C} /{ }^{13} \mathrm{C}$ isotope fractionation resulting from photochemistry and escape. Both the results of Mandt et al. [87] and Nixon et al. [116] fall into the timeline suggested by interior models [160] which suggests that the methane atmosphere is the result of an outgassing episode that occurred between $350 \mathrm{Ma}$ and $1350 \mathrm{Ma}$.

On Titan, both simple (methane, ethane, and propane) and complex hydrocarbons precipitate out of the atmosphere and onto the surface. Measuring the isotopic ratios $\left({ }^{14} \mathrm{~N} /{ }^{15} \mathrm{~N} ;{ }^{12} \mathrm{C} /{ }^{13} \mathrm{C} ; \mathrm{D} / \mathrm{H} ;{ }^{16} \mathrm{O} /{ }^{18} \mathrm{O}\right)$ and abundances of the simple alkanes (e.g., methane, ethane, and propane) will constrain the formation and evolution of the methane cycle 
on Titan. Further measurements of radiogenic noble gases such as ${ }^{40} \mathrm{Ar}$ and ${ }^{22} \mathrm{Ne}$, which are typically markers of volatile elements from Titan's interior can constrain outgassing episodes. Detection of ${ }^{40} \mathrm{Ar}$ and tentatively ${ }^{22} \mathrm{Ne}$ in the atmosphere has provided circumstantial evidence of water-rock interactions and methane outgassing from the interior $[114,161]$. Measurements of the composition and isotopic ratios of Titan's upper atmosphere in a future mission can be used to determine the age of methane in the atmosphere and characterize outgassing history.

On Enceladus, Cassini measurements by INMS [172, 174] and the Ultraviolet Imaging Spectrograph Subsystem (UVIS) [47, 48] showed that plume gas consists primarily of water vapor with a few percent other volatiles (Fig. 7). In addition to $\mathrm{H}_{2} \mathrm{O}$ as the dominant species, INMS was able to identify $\mathrm{CO}_{2}(0.6 \% \pm 0.15 \%), \mathrm{CH}_{4}(0.23 \%$ $\pm 0.06 \%)$, and $\mathrm{NH}_{3}(0.7 \% \pm 0.2 \%)$ in the vapor plume as well as an unidentified species with a mass-to-charge $(\mathrm{m} / \mathrm{z})$ ratio of 28 , which is thought to be either $\mathrm{CO}, \mathrm{N}_{2}, \mathrm{C}_{2} \mathrm{H}_{4}$, or a combination of these compounds. The low mass resolution of Cassini INMS is insufficient to separate these species, and the UVIS measurements can only provide upper limits on $\mathrm{N}_{2}$ and $\mathrm{CO}$ abundance. Determining the abundance ratio between these different species is, however, essential to constrain the origin of volatiles on Enceladus and to assess whether they were reprocessed internally. A high $\mathrm{CO} / \mathrm{N}_{2}$ ratio, for instance, would suggest a cometary-like source with only a moderate modification of the volatile inventory, whereas a low $\mathrm{CO} / \mathrm{N}_{2}$ ratio would indicate a significant internal reprocessing.

In addition to these main volatile species, during some Cassini flybys, the INMS data also indicated the possible presence of trace quantities of $\mathrm{C}_{2} \mathrm{H}_{2}, \mathrm{C}_{3} \mathrm{H}_{8}, \mathrm{C}_{4}$, methanol, formaldehyde, and hydrogen sulfide. Organic species above the INMS mass range of $99 \mathrm{u}$ are also present but could not be further constrained [174]. The identification and the quantification of the abundances of these trace species remains very uncertain due to the limitations of the mass spectrometer on board Cassini.

Except for the measurement of $\mathrm{D} / \mathrm{H}$ in $\mathrm{H}_{2} \mathrm{O}$ on Enceladus (which has large uncertainty, [174]), no information is yet available for the isotopic ratio in Enceladus' plume gas. The baseline mission would determine the isotopic ratios $\left(\mathrm{D} / \mathrm{H},{ }^{12} \mathrm{C} /{ }^{13} \mathrm{C},{ }^{16} \mathrm{O} /{ }^{18} \mathrm{O}\right.$, ${ }^{14} \mathrm{~N} /{ }^{15} \mathrm{~N}$ ) in major gas compounds of Enceladus' plume as well as ${ }^{12} \mathrm{C} /{ }^{13} \mathrm{C}$ in organics contained in icy grains. Comparison of gas isotopic ratios (e.g., $\mathrm{D} / \mathrm{H}$ in $\mathrm{H}_{2} \mathrm{O}$ and $\mathrm{CH}_{4}$, ${ }^{12} \mathrm{C} /{ }^{13} \mathrm{C}$ in $\mathrm{CH}_{4}, \mathrm{CO}_{2}$, and $\mathrm{CO} ;{ }^{16} \mathrm{O} /{ }^{18} \mathrm{O}$ in $\mathrm{H}_{2} \mathrm{O}, \mathrm{CO}_{2}, \mathrm{CO} ;{ }^{14} \mathrm{~N} /{ }^{15} \mathrm{~N}$ in $\mathrm{NH}_{3}$ and $\mathrm{N}_{2}$ ) and with Solar System standards will provide essential constraints on the origin of volatiles and how they may have been internally reprocessed. Simultaneous precise determination of isotopic ratios in N, H, C, and O-bearing species in Enceladus' plume and Titan's atmosphere will permit a better determination of the initial reference values and a quantification of the fractionation due to internal and atmospheric processes on both moons.

Noble gases also provide essential information on how volatiles were delivered to Enceladus and whether significant exchanges between the rock phase and water-ice phase occurred during Enceladus' evolution. The detection and quantification of ${ }^{36} \mathrm{Ar}$ and ${ }^{38} \mathrm{Ar}$ will place fundamental constraints on the volatile delivery in the Saturn system. A low ${ }^{36} \mathrm{Ar} / \mathrm{N}_{2}$ ratio, for instance, would indicate that $\mathrm{N}_{2}$ on Enceladus is not primordial, like on Titan [114], and that the fraction of argon brought by cometary materials on Enceladus is rather low. In addition to argon, if $\mathrm{Ne}, \mathrm{Kr}$, and $\mathrm{Xe}$ are present in detectable 


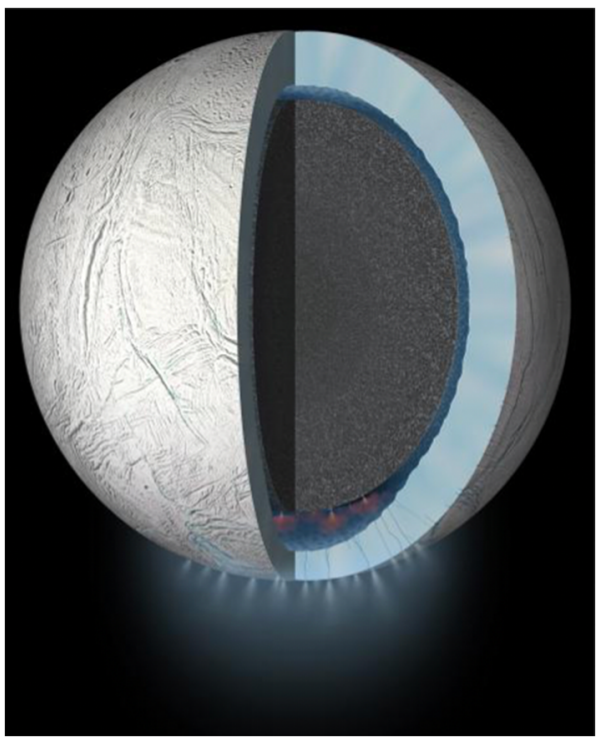

Fig. 7 Enceladus' internal structure inferred from gravity, topography, and libration measurement provided by the Cassini mission. A global subsurface ocean is present under the outer ice shell. The ice shell is believed to be a few kilometers thin at the south polar region where the center of the geological activity is with the formation of the plume formed by multi-jets. Image credit: NASA/JPL-Caltech

amounts, the baseline mission would be able to test whether primordial noble gases on Enceladus were primarily brought by a chondritic phase or cometary ice phase, which has implications for all the other primordial volatiles. The ${ }^{40} \mathrm{Ar} /{ }^{38} \mathrm{Ar} /{ }^{36} \mathrm{Ar}$ as well as ${ }^{20} \mathrm{~N} /$ ${ }^{21} \mathrm{Ne} / 22 \mathrm{Ne}$ measured ratios will also allow for testing of how noble gases were extracted from the rocky core. Abundance ratios between $\mathrm{Ar} / \mathrm{Kr}$ and $\mathrm{Ar} / \mathrm{Xe}$, if $\mathrm{Kr}$ and $\mathrm{Xe}$ are above detection limit, will offer an opportunity to test the influence of clathration storage and decomposition in volatile exchanges through Enceladus's ice shell.

The origin of methane detected in Enceladus' plume is still uncertain. Methane, ubiquitous in the interstellar medium was most likely embedded in the protosolar nebula gas. The inflow of protosolar nebular gas into the Saturn subnebula may have trapped methane in clathrates that were embedded in the planetesimals of Enceladus during their formation. Alternatively, methane may have been produced via hydrothermal reactions in Enceladus' interior. Mousis et al. [107] suggests that if the methane of Enceladus originates from the solar nebula, then $\mathrm{Xe} / \mathrm{H}_{2} \mathrm{O}$ and $\mathrm{Kr} / \mathrm{H}_{2} \mathrm{O}$ ratios are predicted to be equal to $\sim 7 \times 10^{-7}$ and $7 \times 10^{-6}$ in the satellite's interior, respectively. On the other hand, if the methane of Enceladus results from hydrothermal reactions, then $\mathrm{Kr} / \mathrm{H}_{2} \mathrm{O}$ should not exceed $\sim 10^{-10}$ and $\mathrm{Xe} / \mathrm{H}_{2} \mathrm{O}$ should range between $\sim 1 \times 10^{-7}$ and $7 \times 10^{-7}$ in the satellite's interior.

\subsection{Compositional variability in Enceladus' plume}

The detection of salty ice grains $[127,128]$, the high solid-to-vapor ratio $[65,124]$, and the observations of large particles in the lower part of the plume [52] all indicate that the plume of Enceladus originates from a liquid source likely from the subsurface ocean rather than from active melting within the outer ice shell. However, the abundance of 
the major gas species observed by Cassini suggests some contribution from the surrounding cold icy crust should also be considered. Cassini observations show that the plume is made up of $\sim 100$ discrete collimated jets as well as a broad, diffuse component ([48], 2011; [125, 128]). The majority of plume material is found in the distributed diffuse portion of the plume while only a small portion of gas and grains are emitted from the jets $[49,128]$. The saltiness of the ice grains and recent detection of nanometer sized silica dust particles in E-ring stream particles [57, 59] all indicate their origin is a location where alkaline high temperature hydrothermal reactions and likely water-rock interactions are occurring.

Although the Cassini (Cosmic Dust Analyzer) CDA has constrained knowledge of plume compositional stratigraphy, measurements of the absolute abundance and composition of organics, silicates, and salts are poorly constrained given the low spatial resolution $(10 \mathrm{~km})$, low mass resolution, and limited mass range of the CDA. The Cassini INMS provided only plume integrated spectra and is not able to separate gas species with the same nominal mass. However, current high mass resolution, spectrometers have a resolution that is 50 times larger than that of Cassini INMS, and would allow for the separation of isobaric interferences, for example separating ${ }^{13} \mathrm{C}$ and ${ }^{12} \mathrm{CH}$ and $\mathrm{CO}$ and $\mathrm{N}_{2}$. Determining high-resolution spatial variations in composition is crucial to establish whether the jets are fed by a common liquid reservoir or if jet sources are disconnected, and if the local liquid sources interact with a heterogeneous material in the icy shell. Variations in composition between the solid and gas phases as a function of distance from jet sources can also provide information about how the less volatile species condense on the grains, thus constraining the eruption mechanisms.

\subsection{Geological constraints on Titan's methane cycle and surface evolution}

As discussed above, there is an open question on whether Titan's methane-rich atmosphere is being actively replenished, or if methane is being lost and Titan's methane may eventually be depleted [171]. Cryovolcanism has been suggested as a mechanism by which methane and argon can be transported from Titan's interior to its surface (e.g., [72]). Cryovolcanic activity may also promote methane outgassing [160]; while methane clathrates are stable in Titan's ice shell in the absence of destabilizing thermal perturbations and/or pressure variation, variations in the thermal structure of Titan's outer ice shell during its evolution could have produced thermal destabilization of methane clathrates generating outgassing events from the interior to the atmosphere ([160]; see also [32]). A number of candidate cryovolcanic features have been identified in Cassini observations [72]. High-resolution color images from the proposed baseline mission would provide the data needed to determine the geneses of these features. Stratigraphic relationships and crater counting will provide a means by which the relative ages of these features may be constrained.

A related question to the age of Titan's atmosphere is whether Titan's climate is changing. At present, most of the observed liquid methane is located in the north polar region [1]. There have been suggestions, however, that organic seas may have existed in Titan's tropics [85, 104], and/or in broad depressions in the south [1, 52]. Models suggest Titan's methane distribution varies on seasonal timescales (e.g., Hayes [155, 168]) or Milankovitch timescales [1]. Alternative models suggest that methane is being depleted and Titan's atmosphere is drying out [104]. High-resolution images of the 
margins and interiors of these basins will allow us to determine whether they once held seas. Identification of impact features or aeolian processes within these basins will help to constrain the timing of their desiccation.

In addition to their inherent scientific interest, Titan's dunes also serve as a witness plate to climatic evolution. Larger dune forms take longer to form than smaller dune forms. In Earth's Namib desert, these differing timescales result in large, longitudinal dunes that adhere to the overall wind conditions from the Pleistocene 20,000 years ago, while smaller superposing dunes (sometimes called rake dunes, or flanking dunes) have responded to the winds during our current interglacial period accordingly. On Titan, a high-resolution infrared camera could resolve these potential smaller dunes on top of the known longitudinal dunes and will therefore reveal if Titan's recent climate has been stable or if it has changed over the past few Ma. titan's geology is unique in that liquid and solid organics likely play key roles in many of the observed processes. As these processes play an important role in the modification of organics on Titan, both physically and chemically, understanding them is crucial for determining the complex chemistry that likely occurs on this moon. Furthermore, study of Titan's geology allows us to investigate processes that are also common on Earth, but in drastically different environmental conditions, providing a unique way to gain insight into the processes that shaped the Earth and pre-Noachian Mars.

Observations of Titan suggest the landscape is significantly modified by liquid organics (e.g., [17]). Fluvial erosion is observed at all latitudes, with a variety of morphologies suggesting a range of controls and fluvial processes [17]. Highresolution color imaging will provide insight into the nature of this erosion: whether it is predominantly pluvial or sapping in nature and whether it is dominated by mechanical erosion or dissolution. Dissolution processes are suspected to control the landscape of Titan's labyrinth terrains [26] and may also be responsible for the formation of the polar sharp-edged depressions [50], though a new model suggests that the sharp-edged depressions with raised rims may be craters formed by explosions of subsurface pressurized nitrogen during colder methane-depleted periods in Titan's past [103]. High-resolution imaging will allow direct testing of these hypotheses in the proposed baseline mission.

Both fluvial and aeolian processes likely produce and transport sediments on Titan. Dunes are observed across Titan's equator $[86,132]$ while a variety of fluvial sediment deposits can be identified in SAR data $[10,17]$. Detailed imagery of the margins of the dune fields will allow us to determine the source and fate of sands on Titan. Highresolution images will also help determine whether the observed fluvial features are river valleys or channels (see [17]) providing key information in obtaining accurate discharge estimates needed to model sediment transport [16] as well as provide insight into the primary erosion processes acting on crater rims, which are likely composed of a mixture of organics and water ice [111, 112, 143]. Finally, improved imaging will provide insight into the nature of erosion that exists in Titan's mid-latitudes, a region that shows little variability in Cassini observations.

Of great interest in understanding the evolution of Titan's surface is determining the nature of the observed geologic units, including their mechanical and chemical properties. Fluvial processes, the degree to which mechanical vs dissolution dominates and the existence of sapping, reflect the material properties of the surface and therefore can be used as a powerful tool to investigate the properties of the surface. The baseline 
mission imaging would also allow us to investigate the strength of the surface materials by constraining the maximum slopes supported by different geologic units. Highresolution detailed color and stereo imaging of the boundaries of units will also allow investigation of the morphology, topography, and spectral relationship across unit boundaries.

\subsection{Habitability and potential for life in ocean worlds, Enceladus and titan}

Ocean worlds, such as Titan and Enceladus, are objects of wide astrobiological interest because water is one of the key prerequisites for life, in addition to nutrients and energy. Additionally, the organic surface environment of Titan provides an ideal, and in many ways unique setting to investigate the prebiotic chemistry that may have led to the emergence of life on the Earth. Water on ocean worlds in the outer Solar System is found underneath the surface of insulating ice shells, which regulate heat and chemical transport.

The dissipation of energy from tidal flexing, combined with radiogenic energy from these moons' interior provide the energy to sustain these oceans. The presence of antifreeze elements, such as salts or ammonia, suggested by mass spectrometric measurements on Titan and Enceladus [113, 174] and accretion models [81, 105] may also play an important role in sustaining these subsurface oceans. Subsurface oceans are known to exist on both Titan and Enceladus based on Cassini-Huygens mission gravity, shape, and libration data [61-63, 93, 101, 157], compositional in situ measurements and thermal evolution models [98, 159, 160]. Enceladus is unique in that communication of this water is known to exist between the surface and the subsurface and, quite conveniently, this water is ejected into space for easy in situ Sampling. titan provides its own unique environment in which a rich array of complex organics exists on the surface and may interact with the subsurface ocean via cryovolcanic activity or, alternatively, with transient liquid water at the surface following impact events.

Because the presence of a subsurface ocean decouples the interior from the outer ice shell, there is a much larger ice shell deflection and thus enhanced tidal heating and stresses in the shell; therefore tectonic features are much more likely on ocean worlds $[99,115]$ than on icy satellites without subsurface oceans. Surface geological activity may also lead to transport of surface organic material emplaced via precipitation from the atmosphere (e.G. titan) or lodged in the surface as a result of cometary impacts into subsurface oceans. Titan's alkanological cycle and the associated meteorology creates a global distribution of trace species, evident in the formation and dynamics of clouds and an extensive photochemical haze in Titan's atmosphere, which affects the dynamics of how, when, and where organic material settles on the surface and possibly interacts with the subsurface as seen in Fig. 8.

In addition, cometary impacts could deliver key organics such as glycine, the simplest amino acid which has been detected on both comet $67 \mathrm{P} /$ ChuryumovGerasimenko from in situ sampling by ESA's Rosetta mission and on comet 81P/ Wild-2 from samples returned by NASA's Stardust mission. Neish et al. [109] suggested that transient liquid water environments, created by impact melts could be an incubator for the deposited aerosols to create prebiotic chemistry. Further it is likely that such impact melt pools could be stable for $10^{2}-10^{4}$ years [118]. 
This process could be circular; Tobie et al. [161] suggests that some of the species now present in Titan's atmosphere may have originally been dissolved in the subsurface. On smaller ocean worlds such as Europa and Enceladus, the ocean may be in direct contact with the silicate core providing a means of water-rocks interactions [63, 96]. Recent detection of nanometer silica dust particles in Saturn's E-ring is indicative of an origin where alkaline high-temperature water-rock interactions is occurring [59]. The enormous heat output in the south polar terrain, associated with liquid water in contact with rocks, favors prebiotic processes, providing both an energy source and mineral surfaces for catalyzing chemical reactions.

Titan and Enceladus have already demonstrated remarkable astrobiological potential as evidenced by observations of Titan's complex atmosphere and methane cycle, analogous to Earth's water cycle, and Enceladus' cyrovolcanic plume spewing rich organics from the subsurface out into space. Studies of the nature of these organics could tell us whether or not they are biogenic. For instance, part of the $\mathrm{CH}_{4}$ detected in the plume of Enceladus may result from methanogens analogous to those occurring in anaerobic chemosynthetic ecosystems on Earth [91, 152]. A powerful method to distinguish between biogenic and abiogenic $\mathrm{CH}_{4}$ is to analyze the difference in carbon isotope, ${ }^{12} \mathrm{C} /{ }^{13} \mathrm{C}$, between $\mathrm{CH}_{4}$ and a potential source of $\mathrm{C}$, most likely $\mathrm{CO}_{2}$ on Enceladus and Titan, and to analyze the pattern of carbon isotopes in other hydrocarbons, such as $\mathrm{C}_{2} \mathrm{H}_{6}, \mathrm{C}_{2} \mathrm{H}_{4}, \mathrm{C}_{2} \mathrm{H}_{2}, \mathrm{C}_{3} \mathrm{H}_{8}$ etc. [91, 142]. The abundances of other non-methane hydrocarbons relative to methane could also be used to distinguish between biological and other sources [91, 92]. The detection of amino acids could provide additional evidence for active biogenic processes. Even though amino acids can be produced, both biologically and via aqueous alteration of refractory organics, their distribution pattern can confirm if they are of biological origin [34]. Indeed, low molecular weight amino acids, such as glycine and alanine, are kinetically favorable

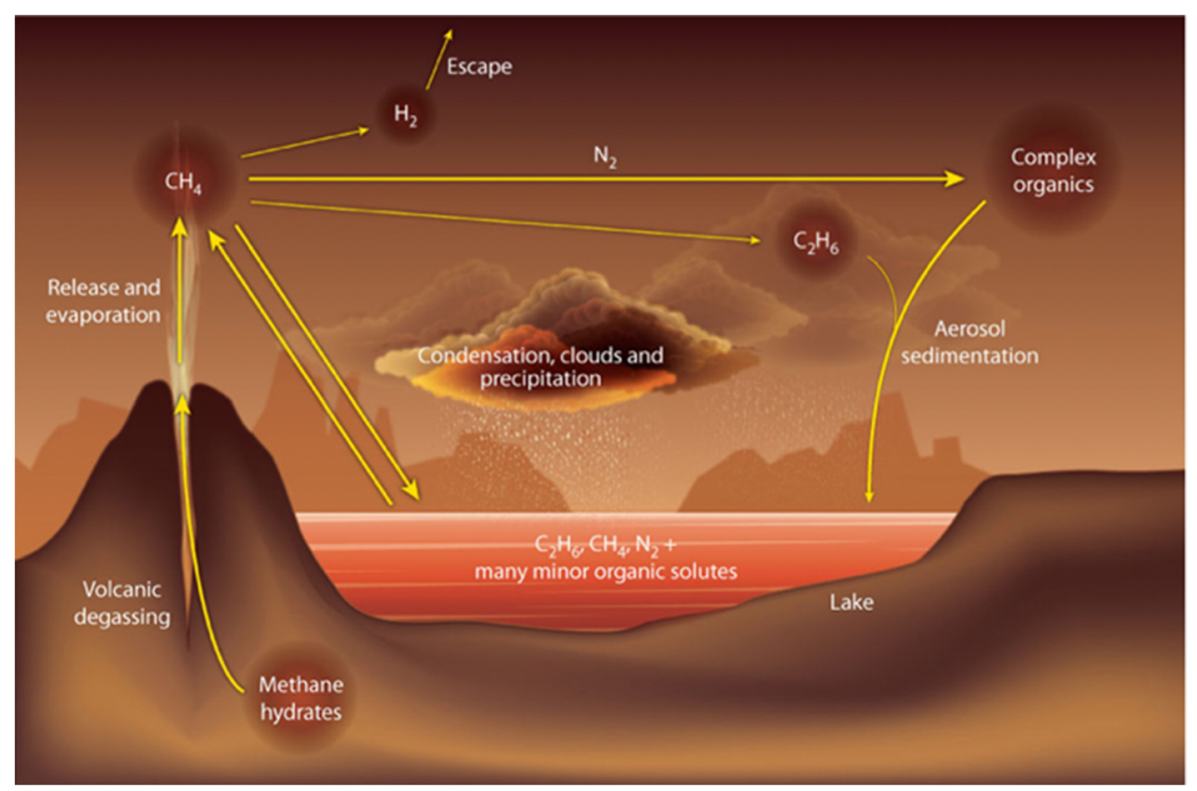

Fig. 8 Titan's methanological cycle [133] 
and therefore dominate any mixture of amino acids synthesized by abiotic process, whereas amino acids resulting from biotic process show a more varied distribution dominated by the protein amino acids in roughly equal proportions [34].

By searching for abnormal isotopic ratios and mass distribution of organic molecules, including amino acids, the proposed baseline mission can determine what chemical processes control the formation and evolution of complex organics on Titan and will test whether biotic processes are currently occurring inside Enceladus. The analysis of salts and minerals embedded in icy grains and their possible distribution throughout the plume will also provide crucial constraints on the nature of hydrothermal activity occurring in Enceladus' deep interior and on how it connects with the plume activity. The observations of Titan's surface will also reveal if active exchange processes with the interior is currently occurring and whether complex organics are potentially in contact with fresh water.

\subsection{Evidence for prebiotic and biotic chemical processes on titan and Enceladus}

Unlike the other ocean worlds in the Solar System, Titan has a substantial atmosphere, consisting of approximately 95\% nitrogen and 5\% methane with trace quantities of hydrogen and its by-products such as hydrocarbons (e.g. ethane, acetylene, propane, and diacetylene) and nitriles, (e.g. hydrogen cyanide $(\mathrm{HCN})$, cyanoacetylene $\left(\mathrm{HC}_{3} \mathrm{~N}\right)$, and cyanogen $\left(\mathrm{C}_{2} \mathrm{~N}_{2}\right)$ ). Somewhat more complex molecules such as vinyl and ethylcyanide follow from these simpler units. In Titan's upper atmosphere, Cassini has detected large organic molecules with high molecular masses over $100 \mathrm{u}$. In situ measurements by the Cassini Plasma Spectrometer (CAPS) detected heavy positive ions (cations) up to $400 \mathrm{u}$ [31] and heavy negative ions (anions) with masses up to $10,000 \mathrm{u}$ [23] in Titan's ionosphere. Whereas Cassini INMS only had the ability to detect cations, current high-resolution mass spectrometer technology can detect both cations and anions with much better mass resolution than Cassini INMS, and even better mass resolution than Cassini CAPS. It is thought that these heavy negative ions, along with other heavy molecules found in the upper atmosphere, are likely the precursors of aerosols that make up Titan's signature orange haze, possibly even precipitating to the surface [164]. While the identities of these molecules are still unknown, their presence suggests a complex atmosphere that could hold the precursors for biological molecules such as those found on Earth. The ability to detect prebiotic molecules in Titan's atmosphere is currently limited by the mass range of the Cassini INMS to the two smallest biological amino acids, glycine (75 u) and alanine (89 $\mathrm{u})$, and the limited mass resolution precludes any firm identification. However, Cassini INMS detected mass spectra fragments for positive ions at masses of $76 \mathrm{u}$ and $90 \mathrm{u}$, which may be consistent with protonated glycine and alanine, respectively [55, 169]. Experimental results from a Titan atmosphere simulation experiment found 18 molecules that could correspond to amino acids and nucleotide bases [55]. The proposed baseline mission would use high-resolution mass spectrometry to measure heavy neutral and ionic constituents up to $1000 \mathrm{u}$, and the elemental chemistry of low-mass organic macromolecules and aerosols in Titan's upper atmosphere as well as monitor neutralionic chemical coupling processes.

The plume emanating from Enceladus' south pole probably contains the most accessible samples from an extra-terrestrial liquid water environment in the Solar 
System. The plume is mainly composed of water vapor and other gases: $0.91 \% \mathrm{H}_{2} \mathrm{O}$, $0.04 \% \mathrm{~N}_{2}, 0.032 \% \mathrm{CO}_{2}, 0.016 \% \mathrm{CH}_{4}$ [172]. In addition, complex macromolecular organic species with masses exceeding $200 \mathrm{u}$, were detected in the plume emissions suggesting the presence of a thin organic-rich film on the upper layer of the ocean [130]. The presence of $\mathrm{CO}_{2}, \mathrm{CH}_{4}$, and $\mathrm{N}_{2}$ can constrain the oxidation state of Enceladus' hydrothermal system during its evolution. The minor gas constituents in the plume are indicative of high-temperature oxidation-reduction (redox) reactions in Enceladus' interior possibly a result of decay of short-lived radionucleides [138]. In addition, $\mathrm{H}_{2}$ production and escape may be a result of redox reactions. Further the high temperatures and $\mathrm{H}_{2}$ escape may have led to the oxidation of $\mathrm{NH}_{3}$ to $\mathrm{N}_{2}$ [39]. Enceladus' redox state may have or have had similarities with terrestrial submarine hydrothermal systems. Detection and inventory of reduced and oxidized species in the plume material (e.g., $\mathrm{NH}_{3} / \mathrm{N}_{2}$ ratio, $\mathrm{H}_{2}$ abundance, reduced versus oxidized organic species) can constrain the redox state and evolution of Enceladus' hydrothermal system.

Cassini CDA measurements identified three types of grains in the plume and Saturn's E-ring. Type I and Type II grains are both salt-poor (Fig. 9). Type I ice grains are nearly pure-water ice while Type II grains also possess silicates and organic compounds and Type III is salt-rich $(0.5-2.0 \%$ by mass $)[127,128]$. The salinity of these particles suggests they originate in a place where likely water-rock interactions are taking place.

In addition, E-ring stream particles were identified as nanometer-sized $\mathrm{SiO}_{2}$ (silica) dust particles that were initially embedded in plume ice grains [59]. These particles indicate an origin at locations where alkaline high temperature $\left(>90^{\circ} \mathrm{C}\right)$ hydrothermal rock-water reactions are taking place [59]. Hsu et al. [59] further suggests that a convective ocean is required to have silica nanoparticles transported from hydrothermal sites at the rocky core up to the surface of the ocean where they can be incorporated into icy plume grains. To confirm this hypothesis of current hydrothermal activity on Enceladus, a direct detection of silica and other minerals within ejected ice grains is required. $\mathrm{SiO}_{2}$ nano-particles detected in Saturn's E-ring can now be much better investigated and quantified by a high-resolution mass spectrometer with a higher dynamic range $\left(10^{6}-10^{8}\right)$. In addition, with high resolution mass spectrometry in the proposed baseline mission it would also be possible to search for signatures of on-going hydrothermal activities from possible detection of native $\mathrm{H}_{2}$ and $\mathrm{He}$.

\subsection{Physical dynamics in Enceladus' plume and Titan's upper atmosphere}

The total heat emission at the south polar "tiger stripes" is at least $5 \mathrm{GW}$ (possibly up to $15 \mathrm{GW},[56])$, and in some of the hot spots where jets emanate, the surface temperatures are as high as $200 \mathrm{~K}$ [41]. Cassini observations show that the plume is made up of $\sim 100$ discrete collimated jets as well as a diffuse distributed component [48, 49, 125 , 128]. The majority of plume material can be found in the distributed diffuse portion of the plume, which likely originates from elongated fissures along Enceladus' tiger stripes while only a small portion of gas and grains are emitted from the jets [49, 128]. CDA measurements demonstrate that the majority of salt-poor grains tend to be ejected through the jets and at faster speeds while larger salt-rich grains tend to be ejected more slowly through the distributed portion of the plume [128]. Ice-to-vapor 

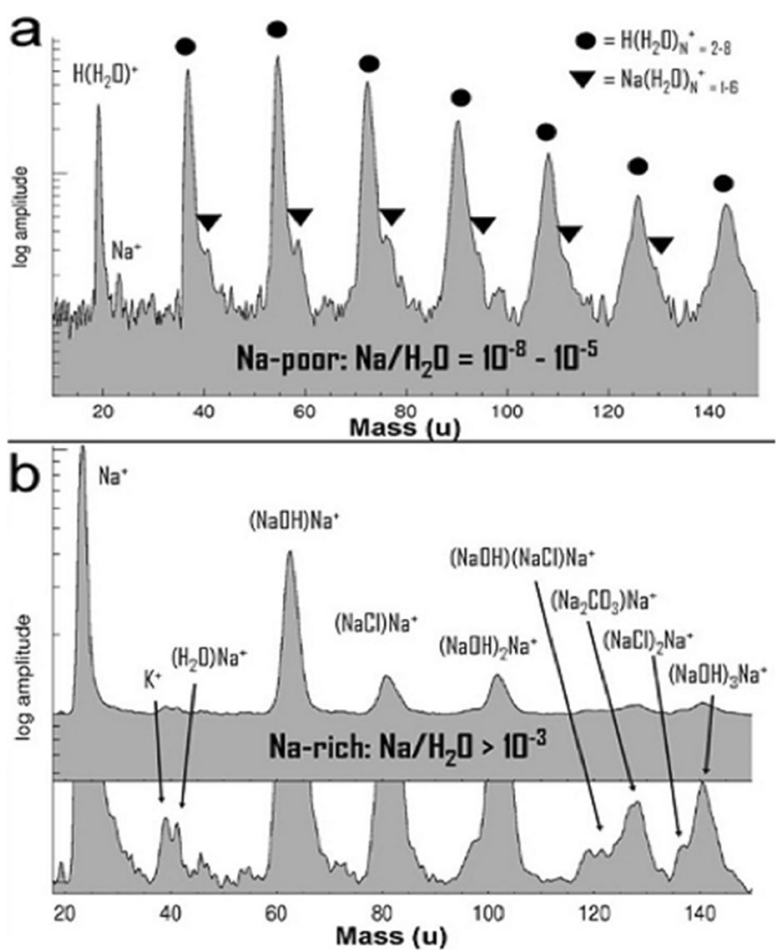

Fig. 9 Composition of salt-poor (Type I and II) and salt-rich (Type III) particles in Saturn's E-ring and Enceladus' plume [128]

ratios can constrain how Enceladus' plume material is formed and transported to the surface. For example, ice-to-vapor ratios $>0.1-0.2$ would exclude plume generation mechanisms which require a large amount of ice grains to be condensed from vapor [65, 124]. However, this ratio is poorly constrained with estimates ranging from 0.05 [136] to 0.4 [124] to $0.35-0.7$ [65]. Imaging and spectral data from the proposed baseline mission could help constrain this important ratio. Cassini ISS images used to track plume brightness variation, which is proportional to the amount of grains in the plume, with the orbital position of Enceladus found more ice grains are emitted when Enceladus is near its farthest point from Saturn (apocenter). It is not understood if the plume vapor has such a variation. This temporal variation of the plume indicates that it is tidally driven but could also be due to possible physical libration [60, 68]. Kite and Rubin [68] have suggested that the tiger stripe fissures are interspersed with vertical pipe-like tubes with wide spacing that extend from the surface to the subsurface water. This mechanism allows tidal forces to turn water motion into heat, generating enough power to produce eruptions in a sustained manner. High spatial resolution thermal emissions maps could be used to constrain the amount of energy dissipated between the tiger stripes.

\subsection{Geological evidence for interior-surface communication on titan}

Geological features such as tectonic and putative cryovolcanic are the reflection of interior processes and may indicate communication between atmosphere, surface and 
subsurface enabling prebiotic or abiotic processes. Titan's surface offers a wealth of geological processes with which to constrain the extent that Titan's surface chemically communicates with its water-rich interior, in particular possible cryovolcanism and tectonics. Also of great importance to habitability are the transient $\mathrm{H}_{2} \mathrm{O}$ melt sheets and flows associated with impacts (e.g. Selk impact crater; [144]). On Titan, several features with volcanic landforms, lengthy flows, tall mountains, and large calderalike depressions, have been identified as possible cryovolcanic sites. At present, the Hotei Regio flows and the Sotra Patera region, which includes Sotra Patera, an elliptical deep depression on Titan, Mohini Fluctus, a lengthy flow feature, and Doom and Erebor Montes, two volcanic edifices, are considered to host the strongest candidates for cyrovolcanism on Titan [72]. High resolution mapping (at minimum, $30 \mathrm{~m} / \mathrm{pixel}$ with digital terrain mapping (DTM) vertical resolution of $10 \mathrm{~m}$ ) of regions that are candidates for cryovolcanic activity could improve the ability to distinguish cryovolcanic features.

A variety of mountainous topography has been observed on Titan [24, 131]. The observed morphologies of many of Titan's mountains suggest contractional tectonism $[70,99]$. This is somewhat surprising, however, in that most tectonic landforms observed on other ocean worlds and icy satellites in the outer Solar System appear to be extensional in nature. Understanding the tectonic regime of Titan is fundamental in understanding the transport of material between the moon's organic-rich surface and subsurface ocean and will also provide insight into the evolution of the other ocean worlds. We will test the hypothesis that Titan's mountains are formed by contraction by mapping the faults driving mountain formation in topographic context. A future mission can test the hypothesis that Titan's mountains are formed by contraction by mapping the faults driving mountain formation in topographic context by using the shape of the fault outcrop draped against topography to measure the faults' dip, which will be $\sim 30$ degrees to the horizontal for compressive mountains and $\sim 60$ degrees for extensional mountains.

In addition to cryovolcanism and tectonism, which may transport water to Titan's surface, impact craters likely have created transient liquid-water environments on Titan's surface. Because of Titan's dense atmosphere, models suggest that melt sheets and flows associated with impact craters may remain liquid for $10^{4}-10^{6}$ years $[2,158]$, though the stability of such lakes is questioned $[140,178]$ and detailed imaging of the floors of young craters is needed to constrain these models.

\section{Science case for the option 1 and 2 mission scenarios}

\subsection{In situ Titan Sea probe/lander}

Titan presents approximately 600 standing bodies of liquid hydrocarbons at the polar regions forming seas and lakes $[73,154]$ which are found poleward of $55^{\circ}$ latitude and cover $1.2 \%$ of the surface that has been observed $(\sim 50 \%)$ by Cassini's instruments $[50$, 52]. Seasonal asymmetry likely due to Saturn's current orbital configuration [1] has resulted in the majority of lakes, filled and empty, being located in the north pole while empty and paleo-lakes predominate in the south pole. In the north, $87 \%$ of the area of observed liquid deposits are contained within the three largest lakes, Ligeia, Kraken, 
and Punga Mare, which are similar in size to the Great Lakes (USA). This hemispheric asymmetry of lakes and seas yields a net transport of volatiles (methane, ethane) from the south to the north; however, as the orbital parameters shift the net flux of northward-bound volatiles is expected to slow and eventually reverse, resulting in a larger southern hemispheric liquid distribution in $\sim 35 \mathrm{kyr}$. If this hypothesis is correct, the distribution of liquid deposits on Titan is expected to move between the poles with a period of $\sim 50 \mathrm{kyr}$ in a process analogous to Croll-Milankovitch cycles on Earth. In situ measurement and comparison between the relative abundance of volatiles that are mobile over these timescales (e.g., methane, ethane) versus those that are involatile (e.g., propane, benzene), can be used to test this hypothesis and understand volatile transport on thousand years timescale. Volatile transport over shorter timescales (diurnal, tidal, and seasonal) can be investigated via in situ measurements of the methane evaporation rate and associated meteorological conditions (e.g., wind speed, temperature, humidity). These measurements can be used to ground-truth methane transport predictions from global climate models (e.g., [95, 137, 162]). Cassini RADAR altimetry results have been used to determine the depth and constrain the composition of the Ligeia Mare [88] and Winnepeg Lacus [89] at the north pole and Ontario Lacus at the south pole [90]. In situ sounding of one of the northern seas can be used to confirm the depth and composition of Ligeia Mare or else to determine the depth of the Kraken Mare, Titan's largest sea, thus improving our understanding of the total volume of liquid available for interaction with the atmosphere. The inventory of methane in Titan's Mare, which requires knowledge of both depth and composition, will provide a lower limit on the length of time that the lakes can sustain methane in Titan's atmosphere [97] and help to quantify the required rate of methane resupply from the interior and/or crust. Similarly, the absolute abundance of methane photolysis products (e.g., ethane, propane) will determine a lower limit for the length of time that methane has been abundant enough to drive photolysis in the upper atmosphere and deposit its products onto the surface and, ultimately, into the lakes and seas.

Similar to the Earth's oceans, Titan's seas record a history of their parent body's origin and evolution. Specifically, the noble gas and isotopic composition of the sea can provide information regarding the origin of Titan's atmosphere, reveal the extent of communication with the interior, potentially constrain the conditions in the Saturn system during formation, and refine estimates of the methane outgassing history. Titan's lakes and seas collect organic material both directly, through atmospheric precipitation of photolysis products, and indirectly, through aeolian or fluvial transport of surface materials (e.g., river systems flowing into the Mare). As a result, the lakes and seas represent the most complete record of Titan's organic complexity and present a natural laboratory for studying prebiotic organic chemistry [82]. Titan's environment is similar to conditions on Earth four billion years ago and presents an opportunity to study active systems involving several key compounds of prebiotic chemistry [29, 133, 139]. Noble gas measurements and, isotopic ratios can also be used to decipher the history of Titan's atmosphere. For example, the ${ }^{13} \mathrm{C} / 12 \mathrm{C}$ ratio of methane was used by Niemann et al. [114] to conclude that methane last outgassed from the interior $\sim 10^{7}$ years ago. However, this calculation assumes that the exposed methane reservoir has an isotopic composition that is in equilibrium with the atmosphere. If the carbon isotope ratio of hydrocarbons in Titan's lakes and seas were found to be 
different than in the atmosphere, it would imply chemical alteration of the isotopic composition and indicate a different timescale for the history of methane-outgassing.

In summary, in situ exploration of Titan's lakes and seas will address fundamental questions involving the origin, evolution, and history of both Titan and the broader Saturnian system. The study of Titan's organic chemistry has direct applicability to our understanding of early prebiotic chemistry on Earth, allowing the investigation of reactions and timescales inaccessible to terrestrial labs.

\subsection{Ice penetrating radar (IPR)}

The ice penetrating radar (IPR) would be capable of both shallow and deep sounding to characterize the subsurface with a depth of $9 \mathrm{~km}$ and $\sim 30 \mathrm{~m}$ vertical resolution at minimum. An IPR can characterize structural, compositional, and thermal variations occurring in the subsurface providing data that can correlate surface and subsurface features and processes, deformation in the upper ice shell, as well as global and local surface age. On Titan, radar sounder observations with a penetration depth up to $\sim 9 \mathrm{~km}$ with a vertical resolution of $\sim 30 \mathrm{~m}$, similar to JUICE RIME and Europa Clipper REASON, could directly determine the relict brittle-ductile transition of the ice shell revealing its thermal state, thus constraining its ice shell thickness and thermal evolution. Liu et al. [70] suggests that subsurface liquid hydrocarbons could enable contractional structures to form on Titan without the necessity of large stresses. An IPR would be able to detect any near surface pockets of liquid. In addition, an IPR would also investigate the ice-ocean interface at Enceladus' SPT and its variability in the SPT.

An additional option for radar architecture could be a multi-mode radar design suitable for both sounding and imaging to be operated in two modes: a vertical sounder mode, with similar capabilities as described above but with different architecture, and a Synthetic Aperture Radar (SAR) imaging mode, similar to Cassini's, but with higher resolution at tens of meters. The additional SAR mode could be used for highresolution imaging of the surface, complementing the IR imaging, as well as for creating three dimensional high resolution bathymetric maps of Titan seas and lakes and could permit investigation of any possible composition variation in space and time of the hydrocarbon liquid and/or sea floor properties.

\section{Conclusions}

A return to the Saturn system with a focus on Titan and Enceladus offers an ideal opportunity to further our knowledge of ocean worlds, a crucial component of ESA's Voyage 2050 plan. The NASA/ESA/ASI Cassini-Huygens and subsequent interplanetary missions have shown that oceans are common in the Solar System and that extra-terrestrial lakes and seas exist, even if in a different form with respect to terrestrial analogues. These two Saturnian moons offer ideal laboratories to study potentially habitable prebiotic environments, understand the processes that shaped ancient Earth and pre-Noachian Mars and further our knowledge of Solar System evolution. In addition, in-situ exploration of Titan's lakes offers an unprecedent opportunity to excite public imagination and interest in space exploration and science. A deeper exploration of the Saturn system will also complement upcoming missions to the outer Solar System, including ESA's JUICE mission and NASA's 
Clipper mission to the Jupiter system and NASA's Dragonfly mission to Titan's Selk crater. In conclusion, further exploration of Titan and Enceladus offers an opportunity to answer many key scientific questions and stimulate public imagination and interest.

Acknowledgments The authors thank the reviewer for the constructive comments.

Funding Open access funding provided by Universit ̃̃ degli Studi G. D'Annunzio Chieti Pescara within the CRUI-CARE Agreement.

Open Access This article is licensed under a Creative Commons Attribution 4.0 International License, which permits use, sharing, adaptation, distribution and reproduction in any medium or format, as long as you give appropriate credit to the original author(s) and the source, provide a link to the Creative Commons licence, and indicate if changes were made. The images or other third party material in this article are included in the article's Creative Commons licence, unless indicated otherwise in a credit line to the material. If material is not included in the article's Creative Commons licence and your intended use is not permitted by statutory regulation or exceeds the permitted use, you will need to obtain permission directly from the copyright holder. To view a copy of this licence, visit http://creativecommons.org/licenses/by/4.0/.

\section{References}

1. Aharonson, O., et al.: An asymmetric distribution of lakes on titan as a possible consequence of orbital forcing. Nat. Geosci. 2, 851-854 (2009)

2. Artemieva, N., Lunine, J.I.: Impact cratering on titan II. Global melt, escaping ejecta, and aqueous alteration of surface organics. Icarus. 175, 522-533 (2005)

3. Atreya, S.K., et al.: Titan's methane cycle. Planetary and Space Science. 54, 1177-1187 (2006)

4. Barco, A., et al. 2019. Design and development of the ESA am-fueled radioisotope power systems. IEEE aerospace conference, 1-11

5. Barnes, J.W., et al.: Cassini/VIMS observes rough surfaces on Titan's Punga Mare in specular reflection. Planetary science. 3(1), 1 (2014)

6. Barnes, J.W., et al.: Organic sedimentary deposits in Titan's dry lakebeds: probable evaporite. Icarus. 216(1), 136-140 (2011)

7. Barnes, J.W., et al.: A transmission spectrum of Titan's north polar atmosphere from a specular reflection of the sun. Astrophys. J. 777, 161 (2013)

8. Beghin, C., et al.: Analytic theory of Titan's Schumann resonance: constraints on ionospheric conductivity and buried water ocean. Icarus. 218, 1028-1042 (2012)

9. Bèzard, B.: The methane mole fraction in Titan's stratosphere from DISR measurements during the Huygens probe's descent. Icarus. 242, 64-73 (2014)

10. Birch, S., et al.: Geomorphologic mapping of Titan's polar terrains: constraining surface processes and landscape evolution. Icarus. 282, 214-236 (2016)

11. Birch, S. P. D. et al. 2018 Raised Rims around Titan's Sharp-Edged Depressions. Geophysical Research Letters 45

12. Blankenship, D. D., et al. 2009. Radar sounding of Europa's subsurface properties and processes: the view from earth. In Europa (pp. 631-654). Univ. Arizona press

13. Brown, R.H., et al.: The identification of liquid ethane in Titan's Ontario lacus. Nature. 454(7204), 607 (2008)

14. Bruzzone, L., et al. 2013. RIME: radar for icy moon exploration. In 2013 IEEE international geoscience and remote sensing symposium- IGARSS (pp. 3907-3910). IEEE

15. Bruzzone, L., et al. 2015. Jupiter icy moon explorer (JUICE): Advances in the design of the radar for icy moons (rime). In 2015 IEEE International Geoscience and Remote Sensing Symposium- IGARSS (pp. 1257-1260)

16. Burr, D.M., et al.: Sediment transport by liquid surficial flow: application to titan. Icarus. 181, 235-242 (2006)

17. Burr, D.M., et al.: Morphology of fluvial networks on titan: evidence for structural control. Icarus. 226, $742-759$ (2013) 
18. Cable, M.L., et al.: Experimental determination of the kinetics of formation of the benzene-ethane cocrystal and implications for titan. Geophys. Res. Lett. 41, 5396-5401 (2014)

19. Cable, M.L., et al. 2020. Properties and Behavior of the Acentonitrile-Acetylene co-Crystal under Titan Surface Conditions. ACS Earth and Space Chemistry

20. Čadek, O., 10 colleagues: Enceladus's internal ocean and ice shell constrained from Cassini gravity, shape, and libration data. Geophys. Res. Lett. 43, 5653-5660 (2016)

21. Čadek, O., et al.: Long-term stability of Enceladus' uneven ice shell. Icarus. 319, 476-484 (2019)

22. Clark, R.N., et al.: Detection and mapping of hydrocarbon deposits on titan. Journal of Geophysical Research: Planets. 115(E10), (2010)

23. Coates, A.J., et al.: Discovery of heavy negative ions in Titan's ionosphere. Geophys. Res. Lett. 34, L22103 (2007)

24. Cook-Hallett, C., et al.: Global contraction/expansion and polar lithospheric thinning on titan from patterns of tectonism. Journal of Geophysical Research (Planets). 120, 1220-1236 (2015)

25. Cordier, D., et al.: About the possible role of Hydrocarbon Lakes in the origin of Titan's Noble gas atmospheric depletion. Astrophys. J. 721, L117-L120 (2010)

26. Cornet, T., et al.: Dissolution on titan and on earth: toward the age of Titan's karstic landscapes. Journal of Geophysical Research (Planets). 120, 1044-1074 (2015)

27. Coustenis, et al.: TandEM: titan and Enceladus mission. Exp. Astron. 23, 893-946 (2009a)

28. Coustenis, A., et al. 2009b. The joint NASA-ESA titan Saturn system Mission (TSSM) study. LPI : 1060

29. Coustenis, A., Raulin, F. 2015. Titan astrobiology. In the encyclopedia of astrobiology, 2nd edition, M. Gargaud, R. Amils, J. Cernicharo, H. J. cleaves II, K. Kobayashi, D. Pinti, M. Viso (Eds), springer, 2550 p., ISBN 978-3-662-44184-8

30. Coustenis, A. 2015. The Cassini-Huygens mission. In the encyclopedia of astrobiology, 2nd edition, M. Gargaud, R. Amils, J. Cernicharo, H. J. cleaves II, K. Kobayashi, D. Pinti, M. Viso (Eds), springer, 2550 p., ISBN 978-3-662-44184-8

31. Crary, F.J., et al.: Heavy ions, temperatures and winds in Titan's ionosphere: combined Cassini CAPS and INMS observations. Planetary and Space Science. 57, 1847-1856 (2009)

32. Davies, A.G., et al.: Cryolava flow destabilization of crustal methane clathrate hydrate on titan. Icarus. 274, 23-32 (2016)

33. Sanctis, D., et al.: Relict Ocean worlds: Ceres. Space Sci. Rev. 216, 60 (2020)

34. Dorn, E.D., Adami, C.: Robust monomer- distribution biosignatures in evolving digital biota. Astrobiology. 11, 959-968 (2011)

35. Dougherty, M.K., et al.: Identification of a dynamic atmosphere at Enceladus with the Cassini magnetometer. Science. 311, 1406-1409 (2006)

36. Dougherty, M.K., et al.: Titan beyond Cassini-Huygens. Titan from Cassini-Huygens. 479-488 (2010)

37. Elachi, C., et al.: Radar: the Cassini titan radar mapper. Space Sci. Rev. 115, 71-110 (2004)

38. Gebara, C. A., et al. 2019. Tensegrity Ocean world landers. In AIAA Scitech 2019 forum (p. 0868)

39. Glein, C.R., et al.: The oxidation state of hydrothermal systems on early Enceladus. Icarus. 197, 157163 (2008)

40. Glein, C.R., et al.: The pH of Enceladus' ocean. Geochim. Cosmochim. Acta. 162, 202-219 (2015)

41. Goguen, J.D., 12 colleagues: The temperature and width of an active fissure on Enceladus measured with Cassini VIMS during the 14 April 2012 south pole flyover. Icarus. 226, 1128-1137 (2013)

42. Griffith, C.A., Zahnle, K.: Influx of cometary volatiles to planetary moons: the atmospheres of 1000 possible titans. J. Geophys. Res. 100, 16907-16922 (1995)

43. Griffith, C. A., et al. 2019. A corridor of exposed ice-rich bedrock across Titan's tropical region. Nature Astronomy, 1

44. Grima, C., et al.: Radar signal propagation through the ionosphere of Europa. Planetary and Space Science. 117, 421-428 (2015)

45. Gudipati, M.S., et al.: Photochemical activity of Titan's low-altitude condensed haze. Nat. Commun. 4, 1648 (2013). https://doi.org/10.1038/ncomms2649

46. Hand, K.P., Sotin, C., Hayes, A., Coustenis, A. 2020. On the habitability and future exploration of ocean worlds. Space science reviews 216, issue 4, 2020:95

47. Hansen, C.J., et al.: Enceladus' water vapor plume. Science. 311, 1422-1425 (2006)

48. Hansen, C.J., et al.: Water vapour jets inside the plume of gas leaving Enceladus. Nature. 456, 477-479 (2008)

49. Hansen, C.J., 10 colleagues: The composition and structure of the Enceladus plume. Geophys. Res. Lett. 38, L11202 (2011)

50. Hayes, A., et al.: Hydrocarbon lakes on titan: distribution and interaction with a porous regolith. Geophys. Res. Lett. 35, L09204 (2008) 
51. Hayes, A.G., et al.: Topographic constraints on the evolution and connectivity of Titan's lacustrine basins. Geophys. Res. Lett. 44(23), 11-745 (2017)

52. Hedman, M.M., et al.: Spectral observations of the Enceladus plume with Cassini-Vims. Astrophys. J. 693, 1749-1762 (2009)

53. Heggy, E., et al.: Ground-penetrating radar sounding in mafic lava flows: assessing attenuation and scattering losses in Mars-analog volcanic terrains. Journal of Geophysical Research: Planets. 111(E6), (2006)

54. Hörst, S.M., et al.: Origin of oxygen species in Titan's atmosphere. Journal of Geophysical Research (Planets). 113, E10006 (2008)

55. Hörst, S.M., and 12 colleagues 2012. Formation of amino acids and nucleotide bases in a titan atmosphere simulation experiment. Astrobiology 12, 809-817

56. Howett, C.J.A., et al.: High heat flow from Enceladus' south polar region measured using $10-600 \mathrm{~cm}^{-1}$ Cassini/CIRS data. Journal of Geophysical Research (Planets). 116, E03003 (2011)

57. Hsu, H.-W., et al.: Stream particles as the probe of the dust-plasma-magnetosphere interaction at Saturn. J. Geophys. Res. Space Physics. 116, A09215 (2011)

58. Hsu, H.-W., et al.: Silica nanoparticles provide evidence for hydrothermal activities at Enceladus. Workshop on the Habitability of Icy Worlds. 1774, 4042 (2014)

59. Hsu, H.-W., 14 colleagues: Ongoing hydrothermal activities within Enceladus. Nature. 519, 207-210 (2015)

60. Hurford, T.A., et al.: Geological implications of a physical libration on Enceladus. Icarus. 203, 541-552 (2009)

61. Iess, L., et al.: Gravity field, shape, and moment of inertia of titan. Science. 327, 1367 (2010)

62. Iess, L., et al.: The tides of titan. Science. 337, 457 (2012)

63. Iess, L., 10 colleagues: The gravity field and interior structure of Enceladus. Science. 344, 78-80 (2014)

64. Ingersoll, A.P., Pankine, A.A.: Subsurface heat transfer on Enceladus: conditions under which melting occurs. Icarus. 206, 594-607 (2010)

65. Ingersoll, A.P., Ewald, S.P.: Total particulate mass in Enceladus plumes and mass of Saturn's E ring inferred from Cassini ISS images. Icarus. 216, 492-506 (2011)

66. Israël, G., et al.: Complex organic matter in Titan's atmospheric aerosols from in situ pyrolysis and analysis. Nature. 438(7069), 796 (2005)

67. Jennings, D.E., et al.: $12 \mathrm{C} / 13 \mathrm{C}$ ratio in ethane on titan and implications for Methane's replenishment. J. Phys. Chem. A. 113, 11101-11106 (2009)

68. Kite, E.S., Rubin, A.M.: Sustained eruptions on Enceladus explained by turbulent dissipation in tiger stripes. Proc. Natl. Acad. Sci. 113, 3972-3975 (2016)

69. Le Gall, A., et al.: Thermally anomalous features in the subsurface of Enceladus's south polar terrain. Nature Astronomy. 1(4), 0063 (2017)

70. Liu, Z.Y.C., et al.: The tectonics of titan: global structural mapping from Cassini RADAR. Icarus. 270, 14-29 (2016)

71. Lopes, R.M.C., 43 colleagues: Cryovolcanic features on Titan's surface as revealed by the Cassini titan radar mapper. Icarus. 186, 395-412 (2007)

72. Lopes, R.M.C., 15 colleagues: Cryovolcanism on titan: new results from Cassini RADAR and VIMS. Journal of Geophysical Research (Planets). 118, 416-435 (2013)

73. Lopes, R.M.C., et al.: Titan as revealed by the Cassini radar. Space Sci. Rev. 215(4), 33 (2019)

74. Lorenz, R.D., 39 colleagues: The sand seas of titan: Cassini RADAR observations of longitudinal dunes. Science. 312, 724-727 (2006)

75. Lorenz, R.D., Newman, C.E.: Twilight on Ligeia: implications of communications geometry and seasonal winds for exploring Titan's seas 2020-2040" advances in space research, 56. Issue. 1, 190204 (2015)

76. Lorenz, R.D., Mann, J.: Seakeeping on Ligeia Mare: dynamic response of a floating capsule to waves on the hydrocarbon seas of Saturn's moon titan. Johns Hopkins/APL Technical Digest. 33(2), 82-94 (2015)

77. Lorenz, R.D., et al.: Instrumented splashdown testing of a scale model titan Mare explorer (tiME) capsule. The Aeronautical Journal. 119(1214), 409-431 (2015)

78. Lorenz, R.D., Cabrol, N.A.: Onboard science insights and vehicle dynamics from scale- model trials of the titan Mare explorer (TIME) capsule at Laguna Negra, Chile. Astrobiology. 18(5), 607-618 (2018)

79. Lorenz, Ralph D., et al. 2018. Dragonfly: a Rotorcraft Lander Concept for Scientific Exploration at Titan. Johns Hopkins APL Technical Digest

80. Lunine, J., et al.: Ethane Ocean on titan. Science. 222, 1229-1230 (1983)

81. Lunine, J.I., Stevenson, D.J.: Clathrate and ammonia hydrates at high pressure - application to the origin of methane on titan. Icarus. 70, 61-77 (1987)

82. Lunine, J., et al.: The origin and evolution of titan. Titan from Cassini-Huygens. 35, (2010)

83. Lunine, J.I.: Ocean worlds exploration. Acta Astronautica. 131, 123-130 (2017) 
84. Lunine, J., et al. 2018. Future exploration of Enceladus and other Saturnian moons. In "Enceladus and the icy moons of Saturn”. LPI/UA/space science series, Paul M. Schenk, Roger N. Clark, Carly J. A. Howett, Anne J. Verbiscer, J. hunter Waite Eds., ISBN 9780816537075

85. MacKenzie, S.M., 10 colleagues: Evidence of Titan's climate history from evaporite distribution. Icarus. 243, 191-207 (2014)

86. Malaska, M.J., et al.: Material transport map of titan: the fate of dunes. Icarus. 270, 183-196 (2016)

87. Mandt, K.E., 18 colleagues: Ion densities and composition of Titan's upper atmosphere derived from the Cassini ion neutral mass spectrometer: analysis methods and comparison of measured ion densities to photochemical model simulations. Journal of Geophysical Research (Planets). 117, E10006 (2012)

88. Mastrogiuseppe, M., et al.: The bathymetry of a Titan Sea. Geophys. Res. Lett. 41, 1432-1437 (2014)

89. Mastrogiuseppe, M., et al.: Deep and methane-rich lakes on titan. Nature Astronomy. 3(6), 535 (2019)

90. Mastrogiuseppe, M., et al.: Bathymetry and composition of Titan's Ontario lacus derived from Monte Carlo-based waveform inversion of Cassini RADAR altimetry data. Icarus. 300, 203-209 (2018)

91. McKay, C.P., et al.: The possible origin and persistence of life on Enceladus and detection of biomarkers in the plume. Astrobiology. 8, 909-919 (2008)

92. McKay, C.P.: Titan as the abode of life. Life. 6, 8 (2016)

93. McKinnon, W.B.: Effect of Enceladus's rapid synchronous spin on interpretation of Cassini gravity. Geophys. Res. Lett. 42, 2137-2143 (2015)

94. Miller, K., et al.: Contributions from accreted organics to Titan's atmosphere: new insights from cometary and chondritic data. Astrophys. J. (2019). https://doi.org/10.3847/1538-4357/aaf561

95. Mitchell, J.L., et al.: The impact of methane thermodynamics on seasonal convection and circulation in a model titan atmosphere. Icarus. 203(1), 250-264 (2009)

96. Mitri, G., Showman, A.P.: Convective conductive transitions and sensitivity of a convecting ice shell to perturbations in heat flux and tidal-heating rate: implications for Europa. Icarus. 177, 447-460 (2005)

97. Mitri, G., et al.: Hydrocarbon lakes on titan. Icarus. 186, 385-394 (2007)

98. Mitri, G., Showman, A.P.: Thermal convection in ice-I shells of titan and Enceladus. Icarus. 193(2), 387-396 (2008)

99. Mitri, G., et al.: Mountains on titan: modeling and observations. Journal of Geophysical Research (Planets). 115, E10002 (2010)

100. Mitri, G., 16 colleagues: The exploration of titan with an orbiter and a lake probe. Planetary and Space Science. 104, 78-92 (2014)

101. Mitri, G., et al.: Shape, topography, gravity anomalies and tidal deformation of titan. Icarus. 236, 169177 (2014)

102. Mitri, G., et al.: Explorer of Enceladus and titan (E2T): investigating ocean worlds' evolution and habitability in the solar system. Planetary and space science. 155, 73-90 (2018)

103. Mitri, G., et al.: Possible explosive crater origin of small lake basins with raised rims on titan. Nat. Geosci. 12, 791-796 (2019)

104. Moore, J.M., Howard, A.D.: Are the basins of Titan's Hotei Regio and Tui Regio sites of former low latitude seas? Geophys. Res. Lett. 37, L22205 (2010)

105. Mousis, O., et al.: An evolutionary turbulent model of Saturn's subnebula: implications for the origin of the atmosphere of titan. Icarus. 156, 162-175 (2002)

106. Mousis, O., Schmitt, B.: Sequestration of ethane in the Cryovolcanic subsurface of titan. Astrophys. J. 677, L67 (2008)

107. Mousis, O., 10 colleagues: Clathration of volatiles in the solar nebula and implications for the origin of Titan's atmosphere. Astrophys. J. 691, 1780-1786 (2009)

108. Mousis, O., et al:: Removal of Titan's atmospheric Noble gases by their sequestration in surface clathrates. Astrophys. J. 740, L9 (2011)

109. Neish, C.D., et al.: Titan's primordial soup: formation of amino acids via low-temperature hydrolysis of Tholins. Astrobiology. 10, 337-347 (2010)

110. Neish, C.D., Lorenz, R.D.: Titan's global crater population: a new assessment. Planetary and Space Science. 60, 26-33 (2012)

111. Neish, C.D., 14 colleagues: Spectral properties of Titan's impact craters imply chemical weathering of its surface. Geophys. Res. Lett. 42, 3746-3754 (2015)

112. Neish, C.D., et al.: Fluvial erosion as a mechanism for crater modification on titan. Icarus. 270, 114-129 (2016)

113. Niemann, H.B., 17 colleagues: The abundances of constituents of Titan's atmosphere from the GCMS instrument on the Huygens probe. Nature. 438, 779-784 (2005) 
114. Niemann, H.B., et al.: Composition of Titan's lower atmosphere and simple surface volatiles as measured by the Cassini-Huygens probe gas chromatograph mass spectrometer experiment. Journal of Geophysical Research (Planets). 115, E12006 (2010)

115. Nimmo, F., Pappalardo, R.T.: Ocean worlds in the outer solar system. J. Geophys. Res. 121(8), 13781399 (2016)

116. Nixon, C.A., 12 colleagues: Isotopic ratios in Titan's methane: measurements and modeling. Astrophys. J. 749, 159 (2012)

117. Nixon, C.A., et al.: Titan's cold case files- outstanding questions after Cassini-Huygens. Planetary and Space Science. 155, 50 (2018)

118. O'Brien, D.P., et al.: Numerical calculations of the longevity of impact oases on titan. Icarus. 173, 243$253(2005)$

119. Ono, T., et al. 2010. The lunar radar sounder (LRS) onboard the KAGUY a (SELENE) spacecraft. Space Science Reviews154.1-4, 145-192

120. Oriti, S., Schmitz, P. 2019. Dynamic RPS Path to Flight

121. Owen, T., Niemann, H.B.: The origin of Titan's atmosphere: some recent advances. Philos. Trans. R. Soc. Lond. A. 367, 607-615 (2009)

122. Picardi, G., et al.: Performance and surface scattering models for the Mars advanced radar for subsurface and ionosphere sounding (MARSIS). Planetary and Space Science. 52(1-3), 149-156 (2004)

123. Poggiali, V., et al.: Liquid-filled canyons on titan. Geophys. Res. Lett. 43(15), 7887-7894 (2016)

124. Porco, C.C., 24 colleagues: Cassini observes the active south pole of Enceladus. Science. 311, 13931401 (2006)

125. Porco, C., et al.: How the geysers, tidal stresses, and thermal emission across the south polar terrain of Enceladus are related. Astron. J. 148, 45 (2014)

126. Postberg, F., et al.: The E-ring in the vicinity of Enceladus. II. Probing the moon's interior. The composition of E-ring particles. Icarus. 193, 438-454 (2008)

127. Postberg, F., et al.: Sodium salts in E-ring ice grains from an ocean below the surface of Enceladus. Nature. 459, 1098-1101 (2009)

128. Postberg, F., et al.: A salt-water reservoir as the source of a compositionally stratified plume on Enceladus. Nature. 474, 620-622 (2011)

129. Postberg, F., et al. 2015. Refractory Organic Compounds in Enceladus' Ice Grains and Hydrothermal Activity. AGU Fall Meeting Abstracts

130. Postberg, F., et al.: Macromolecular organic compounds from the depths of Enceladus. Nature. 558, 564-568 (2018)

131. Radebaugh, J., et al.: Mountains on titan observed by Cassini radar. Icarus. 192, 77-91 (2007)

132. Radebaugh, J., 15 colleagues: Dunes on titan observed by Cassini radar. Icarus. 194, 690-703 (2008)

133. Raulin, F.: Organic lakes on titan. Nature. 454, 587-589 (2008)

134. Roth, L., et al.: Transient water vapor at Europa's south pole. Science. 343, 171-174 (2014)

135. Roth, L., et al.: Detection of a hydrogen corona in HST Ly $\alpha$ images of Europa in transit of Jupiter. Astron. J. 153(2), 67 (2017)

136. Schmidt, J., et al.: Slow dust in Enceladus' plume from condensation and wall collisions in tiger stripe fractures. Nature. 451, 685-688 (2008)

137. Schneider, T., et al.: Polar methane accumulation and rainstorms on titan from simulations of the methane cycle. Nature. 481(7379), 58 (2012)

138. Schubert, G., et al.: Enceladus: present internal structure and differentiation by early and long-term radiogenic heating. Icarus. 188, 345-355 (2007)

139. Schulze-Makuch, D., Grinspoon, D.H.: Biologically enhanced energy and carbon cycling on titan? Astrobiology. 5(4), 560-567 (2005)

140. Senft, L.E., Stewart, S.T.: Modeling the morphological diversity of impact craters on icy satellites. Icarus. 214, 67-81 (2011)

141. Seu, R., et al.: SHARAD sounding radar on the Mars reconnaissance orbiter. Journal of Geophysical Research: Planets. 112(E5), (2007)

142. Sherwood, L., et al.: Abiogenic formation of alkanes in the Earth's crust as a minor source for global hydrocarbon reservoirs. Nature. 416, 522-524 (2002)

143. Soderblom, L.A., 26 colleagues: Correlations between Cassini VIMS spectra and RADAR SAR images: implications for Titan's surface composition and the character of the Huygens probe landing site. Planetary and Space Science. 55, 2025-2036 (2007)

144. Soderblom, J.M., et al.: Geology of the Selk crater region on titan from Cassini VIMS observations. Icarus. 208, 905-912 (2010) 
145. Soderblom, L.A., et al.: Triton's geyser-like plumes - discovery and basic characterization. Science. 250, 410-415 (1990)

146. Soderblom, J.M., et al.: Modeling specular reflections from hydrocarbon lakes on titan. Icarus. 220(2), 744-751 (2012)

147. Solomonidou, A., et al.: Spectral and emissivity analysis of the raised ramparts around Titan's northern lakes. Icarus. 344, 113338 (2019)

148. Sotin, C., Mitri, G., Rappaport, N., Schubert, G., Stevenson, D. 2009. Titan's interior structure. In Titan from Cassini-Huygens (pp. 61-73). Springer, Dordrecht

149. Sotin, C., et al.: JET: journey to Enceladus and titan. LPI. 1608, 1326 (2011)

150. Spahn, F., 15 colleagues: Cassini dust measurements at Enceladus and implications for the origin of the E ring. Science. 311, 1416-1418 (2006)

151. Spilker, L.: Cassini-Huygens' exploration of the Saturn system: 13 years of discovery. Science. 364(6445), 1046-1051 (2019)

152. Stevens, T.O., McKinley, J.P.: Lithoautotrophic Microbia, ecosystems in deep basalt aquifers. Science. 270, 450-454 (1995)

153. Stevenson, J., et al.: Membrane alternatives in worlds without oxygen: creation of an azotosome. Sci. Adv. 1(1), e1400067 (2015)

154. Stofan, E.R., 37 colleagues: The lakes of titan. Nature. 445, 61-64 (2007)

155. Stofan, E. R et al., 2010. Exploring the seas of titan: the titan Mare Eplorer (TiME) mission. 41st Lunar and Planetary Science Conference, 1-5 Mar 2010, Houston, Texas

156. Tajeddine, R., et al.: True polar wander of Enceladus from topographic data. Icarus. 295, 46 (2017)

157. Thomas, P.C., et al.: Enceladus's measured physical libration requires a global subsurface ocean. Icarus. 264, 37-47 (2016)

158. Thompson, W.R., Sagan, C. 1992. Organic chemistry on titan: surface interactions. Symposium on titan 338

159. Tobie, G., et al.: Titan's internal structure inferred from a coupled thermal-orbital model. Icarus. 175, 496-502 (2005)

160. Tobie, G., et al.: Episodic outgassing as the origin of atmospheric methane on titan. Nature. 440, 61-64 (2006)

161. Tobie, G., et al.: Titan's bulk composition constrained by Cassini-Huygens: implication for internal outgassing. Astrophys. J. 752, 125 (2012)

162. Tokano, T.: Impact of seas/lakes on polar meteorology of titan: simulation by a coupled GCM-Sea model. Icarus. 204(2), 619-636 (2009)

163. Tomasko, M.G., 39 colleagues: Rain, winds and haze during the Huygens probe's descent to Titan's surface. Nature. 438, 765-778 (2005)

164. Tomasko, M.G., West, R.A.: Aerosols in Titan's Atmosphere, pp. 297-321. Titan from CassiniHuygens. Springer (2009)

165. Tortora, P., et al.: Titan gravity investigation with the Oceanus mission. Geophysical research abstracts. Vol. 19, EGU2017-EG17876 (2017)

166. Tortora, P., et al.: Titan gravity investigation from a SmallSat satellite-to-satellite tracking Mission. Geophys. Res. Abstr. 20, EGU2018-EG14126 (2018a)

167. Tortora, P. et al. 2018b. Ocean worlds gravity investigation using SmallSat missions. In 42nd COSPAR Scientific Assembly (Vol. 42)

168. Turtle, E.P., 13 colleagues: Rapid and extensive surface changes near Titan's equator: evidence of April showers. Science. 331, 1414 (2011)

169. Vuitton, V., et al.: Ion chemistry and N-containing molecules in Titan's upper atmosphere. Icarus. 191, 722-742 (2007)

170. Yelle, R.V., et al.: Methane escape from Titan's atmosphere. Journal of Geophysical Research (Planets). 113, E10003 (2008)

171. Yung, Y.L., et al.: Photochemistry of the atmosphere of titan - comparison between model and observations. Astrophys. J. Suppl. Ser. 55, 465-506 (1984)

172. Waite, J.H., 13 colleagues: Cassini ion and neutral mass spectrometer: Enceladus plume composition and structure. Science. 311, 1419-1422 (2006)

173. Waite, J.H., et al.: The process of Tholin formation in Titan's upper atmosphere. Science. 316, 870 (2007)

174. Waite Jr., J.H., 15 colleagues: Liquid water on Enceladus from observations of ammonia and 40Ar in the plume. Nature. 460, 487-490 (2009)

175. Wilson, E.H., Atreya, S.K.: Titan's carbon budget and the case of the missing ethane. J. Phys. Chem. A. 113, 11221-11226 (2009)

176. Wood, C.A., et al.: Impact craters on titan. Icarus. 206, 334-344 (2010) 
177. Zahnle, K., et al.: Impact-generated atmospheres over titan, Ganymede, and Callisto. Icarus. 95, 1-23 (1992)

178. Zahnle, K.J., et al.: Transient climate effects of large impacts on titan. Icarus. 229, 378-391 (2014)

Publisher's note Springer Nature remains neutral with regard to jurisdictional claims in published maps and institutional affiliations.

\section{Affiliations}

Giuseppe Mitri ${ }^{1,2} \cdot$ Jason Barnes $^{3} \cdot$ Athena Coustenis $^{4} \cdot$ Enrico Flamini $^{1}$. Alexander Hayes ${ }^{5} \cdot$ Ralph D. Lorenz ${ }^{6} \cdot$ Marco Mastrogiuseppe $^{7} \cdot$ Roberto Orosei $^{8} \cdot$ Frank Postberg $^{9} \cdot \mathrm{Kim}^{\text {Reh }}{ }^{10} \cdot$ Jason M. Soderblom ${ }^{11} \cdot$ Christophe $^{2}$ Sotin $^{10} \cdot$ Gabriel Tobie $^{12} \cdot$ Paolo Tortora ${ }^{13} \cdot$ Veronique Vuitton $^{14} \cdot$ Peter Wurz $^{15}$

1 International Research School of Planetary Sciences, Pescara, Italy

2 Dipartimento di Ingegneria e Geologia, Università d'Annunzio, Viale Pindaro 42, 65127 Pescara, Italy

3 University of Idaho, Moscow, ID, USA

4 LESIA, Observatoire de Paris, Paris, France

5 Cornell University, Ithaca, NY, USA

6 JHU Applied Physics Lab, Laurel, MD, USA

7 Università La Sapienza, Rome, Italy

8 INAF, Rome, Italy

9 University of Heidelberg, Heidelberg, Germany

10 Jet Propulsion Laboratory, Pasadena, CA, USA

11 Massachusetts Institute of Technology, Cambridge, MA, USA

12 Université de Nantes, Nantes, France

13 University of Bologna, Bologna, Italy

14 University Grenoble Alpes, CNRS, CNES, IPAG, Grenoble, France

15 University of Bern, Bern, Switzerland 